Osorno Covarrubia, J., Couturier S., López Quiroz P., Ferrari L., Martínez Zazueta, I., (2018):Terra Digitalis: diseño e implementación de una revista internacional interactiva de mapas arbitrados", GeoFocus (Artículos), $n^{\circ} 22$, p. 115-139. ISSN: 1578-5157 http://dx.doi.org/10.21138/GF.555

\title{
TERRA DIGITALIS: \\ DISEÑO E IMPLEMENTACIÓN DE UNA REVISTA INTERNACIONAL INTERACTIVA DE MAPAS ARBITRADOS
}

\author{
JAVIER OSORNO COVARRUBIAS ${ }^{1}$, STEPHANE COUTURIER ${ }^{1}$, PENELOPE LÓPEZ $^{2}$ \\ QUIROZ ${ }^{2}$, LUCA FERRARI ${ }^{3}$, IVÁN MARTÍNEZ ZAZUETA ${ }^{4}$ \\ ${ }^{1}$ Laboratorio de Análisis Geoespacial (LAGE). Inst. de Geografía. Circuito Exterior s/n, \\ Cd. Universitaria, Universidad Nacional Autónoma de México, 04510 Ciudad de México, \\ México \\ fjosorno@yahoo.com.mx, stephcamelo@mailcity.com \\ ${ }^{2}$ Laboratorio de Geomática. Centro de Geociencias, Universidad Nacional Autónoma de \\ México, Blvd. Juriquilla 3001, Juriquilla La Mesa, 76230 Juriquilla, Qro., México \\ penelope@geociencias.unam.mx \\ ${ }^{3}$ Departamento de Geología Regional Instituto de Geología. Centro de Geociencias Universidad \\ Nacional Autónoma de México Ciudad Universitaria. 04510 México, D.F. \\ luca@unam.mx, \\ ${ }^{4}$ Centro de Geociencias, Universidad Nacional Autónoma de México. Blvd. Juriquilla 3001, \\ Juriquilla La Mesa, 76230 Juriquilla, Qro., México \\ nose.ivan@gmail.com
}

\section{RESUMEN}

A pesar de su relevancia como herramienta de comunicación científica en las geociencias, en las revistas arbitradas, el mapa es considerado comúnmente un producto secundario. A ello contribuyen seguramente limitaciones de formato y costo inherentes a las publicaciones impresas. Sin embargo, avances recientes en los ámbitos de la cibercartografía y la geoinformática extienden al Internet las capacidades de comunicación de la cartografía digital, habilitando: 1) la visualización fluida de mapas de muy alta resolución 2) la inclusión de contenidos interactivos georreferenciados tales como animaciones, gráficas, videos y visualizaciones 3D 3) la interacción con los datos subyacentes y 4) el acceso a colecciones de datos geocientíficos y su uso distribuido. En este artículo presentamos el diseño e implementación innovadora de una revista científica de mapas arbitrados, que integra los elementos referidos.

Palabras clave: mapas científicos, Cibercartografía, servicios OGC, Open Journal System, Geociencias. 
Osorno Covarrubia, J., Couturier S., López Quiroz P., Ferrari L., Martínez Zazueta, I., (2018):Terra Digitalis: diseño e implementación de una revista internacional interactiva de mapas arbitrados", GeoFocus (Artículos), $n^{\circ} 22$, p. 115-139. ISSN: 1578-5157 http://dx.doi.org/10.21138/GF.555

\title{
TERRA DIGITALIS: DESIGN AND IMPLEMENTATION OF AN INTERACTIVE PEER REVIEWED JOURNAL OF MAPS
}

\begin{abstract}
Despite of its relevance as a tool for scientific communication in Geo-sciences, maps are generally regarded as a secondary product in peer reviewed journals. This limitation may be due to format and cost limitations of printed publications. Advances in cybercartography and geoinformatics extends the online capabilities of cartography, allowing 1) fluid visualization of very high resolution maps 2) easy interaction with the underlying data 3) appropriate interaction with multimedia resources such as graphs, videos and 3Dvisualizations, and 4) remote access to geo-scientific data collections. We present here an innovative design and implementation of an interactive peer reviewed journal of maps which includes the referred capabilities.
\end{abstract}

Keywords: scientific maps, Cybercartography, Open Journal System, OGC services, Geosciences

\section{Introducción}

\subsection{De la cartografía en papel a la "Tierra Digital"}

El mapa — como producto científico que sistematiza, documenta y comunica las relaciones geométricas y topológicas entre una selección de entidades georreferidas a una porción del planeta, dio un salto cualitativo al volverse electrónico y numérico (Dodge, 2017). Con el advenimiento de Internet ocurrió otro avance decisivo que transformó el mapa digital en un producto interactivo que opera como una ventana a las bases de datos subyacentes y da pie a productos cartográficos distribuidos (Kraak \& Brown, 2003; Neumann, 2008). Otro salto radical aún en curso, se deriva de la proliferación de sensores locales y remotos, enlazados en redes que habilitan la actualización y seguimiento casi-en-tiempo-real de un flujo caudaloso de datos, a medida que cambian en el espacio y en el tiempo (Baranovsky \& Zharikova, 2014; OsornoCovarrubias et al., 2015).

A esta réplica emergente, viva, global, continua y multiescalar del planeta alude el concepto de "Digital Earth" (Tierra Digital; ver Plewe, 2007). Su materialización ha inspirado numerosos artículos científicos (Caron et al., 2008, Goodchild, 2012; Craglia, 2012), el nombre de una revista arbitrada de alto impacto - el "International Journal of Digital Earth", el nombre y los objetivos de una de las sociedades científicas más relevantes en el campo de las Ciencias de la Información Geográfica, la "International Society for Digital Earth" y el título de nuestra revista "Terra Digitalis".

Las nuevas tecnologías de cómputo y telecomunicaciones revolucionan la cartografía. Los retos que enfrenta esta disciplina son no son solo técnicos, sin conceptuales. Taylor propone la noción de ciber-cartografía como la "organización, presentación, análisis y comunicación de datos georreferenciados, sobre una amplia variedad de tópicos, intereses y usos, en forma dinámica, multimedia, multisensorial y multidisciplinaria" (Taylor, 2003). Por supuesto la comunicación científica de información georreferenciada dista aún de cumplir con estas características, sin embargo, argumentamos, nuestra revista constituye un avance en la dirección correcta y adoptamos el paradigma de la ciber-cartografía como brújula conceptual.

La transparencia, apertura y reproducibilidad son características vitales del conocimiento científico (Nosek, et al. 2015). Por ello otra directriz distintiva del diseño de 
Osorno Covarrubia, J., Couturier S., López Quiroz P., Ferrari L., Martínez Zazueta, I., (2018):Terra Digitalis: diseño e implementación de una revista internacional interactiva de mapas arbitrados", GeoFocus (Artículos), $n^{\circ} 22$, p. 115-139. ISSN: 1578-5157 http://dx.doi.org/10.21138/GF.555

nuestra revista es la de ofrecer acceso abierto a los mapas y colecciones de datos que publiquemos, a través de estándares geoespaciales de interoperabilidad. El concepto de Infraestructura de datos espaciales (IDE), entendido como el conjunto de tecnologías para "...adquirir, procesar, distribuir, utilizar, mantener y preservar datos espaciales" (The White House, 2002), constituye un referente útil contextualizar nuestra propuesta.

\subsection{Antecedentes tecnológicos para la gestión de revistas arbitradas}

La gestión de una revista científica es una tarea laboriosa y compleja en la que se precisa administrar un dialogo estructurado, "doble ciego" entre autores y revisores pares, editores y maquetadores, con el fin de obtener comunicaciones validadas a través de un proceso de arbitraje riguroso, de acuerdo a los estándares de la misma. La figura 1 resume los principales actores y elementos del proceso editorial.

La edición de este tipo revistas se simplifica y democratiza a través de uso de software. El sistema Open Journal Systems (OJS) ofrece una alternativa que habilita la interacción asíncrona y distribuida de los diferentes actores, a través de Internet, así como el registro de sus interacciones y el reflejo de las mismas en los productos intermedios y finales del proceso. Al ser un sistema abierto y gratuito, es una opción atractiva para instituciones académicas con recursos económicos limitados. El proyecto OJS se planta como objetivo, generar medios tecnológicos para "...impulsar una nueva generación de revistas científicas comprometidas con la filosofía de acceso abierto..." (Laakso et al., 2011). Una valoración cuidadosa de este sistema (Edgar \& Willinsky, 2010), encuentra que es un software robusto con características muy favorables en términos de funcionalidad, estabilidad y extensibilidad.

Por nuestra parte consideramos que la implementación en OJS del proceso editorial es muy completa y funciona muy bien para publicaciones científicas basadas en texto. Sin embargo, el sistema tal y como está presenta lagunas y deficiencias para una revista que se propone de manera explícita, retomando la idea de Origel y Ferrari. (Origel et al., 2009), de "...rescatar el valor científico de la cartografía y optimizar la distribución de mapas arbitrados utilizando las tecnologías Web más recientes".

El mapa como documento digital, suele dar origen a archivos mucho más pesados que los documentos de texto. Por su tamaño "impreso", densidad diversidad de elementos gráficos y carácter eminentemente visual, el mapa requiere una resolución mucho más alta. Aunque los principales navegadores de internet (Google Chrome, Firefox, Internet Explorer, Edge etc.) proveen de herramientas simples para visualizar archivos PDF, éstas presentan limitaciones comunes para el despliegue y visualización de documentos cartográficos de confección rigurosa y alta resolución (Iosifescu-Enescu et al., 2010). Otra desventaja medular reside en el hecho de que al convertir un mapa editado en un Sistema de Información Geográfica a formato PDF, se pierde la conexión a los datos subyacentes y las posibilidades de despliegue e interacción concomitantes. 
Osorno Covarrubia, J., Couturier S., López Quiroz P., Ferrari L., Martínez Zazueta, I., (2018):Terra Digitalis: diseño e implementación de una revista internacional interactiva de mapas arbitrados", GeoFocus (Artículos), $n^{\circ} 22$, p. 115-139. ISSN: 1578-5157 http://dx.doi.org/10.21138/GF.555

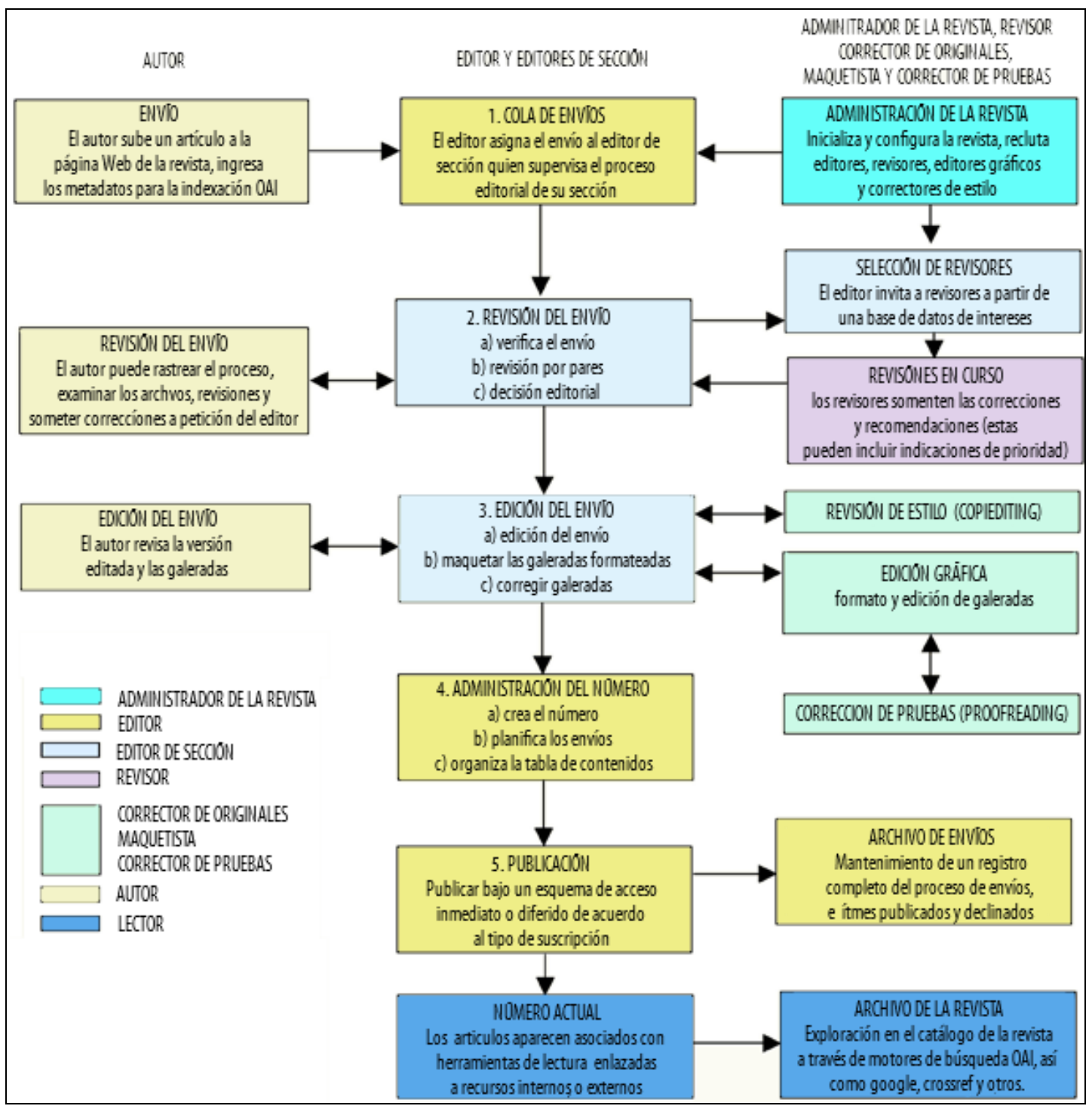

Figura 1. Síntesis de la secuencia de procesos y roles involucrados en la gestión de una revista científica arbitrada (traducido de Muir et al. 2005).

Este artículo presenta una iniciativa del Centro de Geociencias y el Instituto de Geografía de la Universidad Nacional Autónoma de México (UNAM) para establecer la revista internacional arbitrada de mapas digitales interactivos Terra Digitalis (http://terradigitalis.unam.mx). En la segunda sección formulamos los requerimientos de una revista de esta naturaleza y los contrastamos con los de una orientada a la publicación de textos basada en OJS. Identificamos qué funcionalidades de este sistema se pueden utilizar tal como están y cuáles deben extenderse para una publicación de mapas. También, valoramos las modalidades de publicación de la única revista indexada existente de mapas arbitrados el "Journal of Maps" (Journal of Maps, 2017), y discutimos sus limitaciones. En la tercera sección, se propone la estructura y organización de la revista Terra Digitalis. En la cuarta, se presenta el diseño de la interfaz de la revista, y funcionalidades que habilitan la visualización de productos cartográficos de alta calidad, así como la gestión y acceso a de conjuntos de datos espaciales. En la quinta se presentan los resultados alcanzados a la fecha de envío de este artículo. Finalmente se discute el potencial de esta iniciativa para la comunidad internacional de geociencias. 
Osorno Covarrubia, J., Couturier S., López Quiroz P., Ferrari L., Martínez Zazueta, I., (2018):Terra Digitalis: diseño e implementación de una revista internacional interactiva de mapas arbitrados", GeoFocus (Artículos), $n^{\circ} 22$, p. 115-139. ISSN: 1578-5157 http://dx.doi.org/10.21138/GF.555

\section{Estado de la cuestión y requerimientos de una revista de mapas en línea}

Para nuestra revista decidimos partir del sistema OJS y extender su funcionalidad para habilitar la publicación de mapas y datos geoespaciales.

2.1. Extensiones al flujo de procesos, necesarias para una revista de mapas y datos geoespaciales.

Nuestra revista extendería el tipo de productos arbitrados publicables a los siguientes productos cartográficos:

1. mapa estático: equivalente al mapa impreso, en formato digital de muy alta resolución

2. mapa interactivo: mapa 2D, opcionalmente multi-escala, con la capacidad de prender y apagar capas, y realizar consultas sencillas.

3. mapa dinámico: visualizador de secuencias espacio-temporales de datos geoespaciales, estructuras basados en estructuras raster o vectoriales.

4. mapa 3D: visualizador que permita observar en perspectiva las capas superpuestas sobre el relieve, controlando de manera fluida el punto de vista desde el cual se observa la escena

5. colección de datos geoespaciales: acceso a una colección publicada en nuestros servidores a través de conexiones OGC $^{2}$

6. reseña de servicio OGC: Reseña de un servicio público, relevante para la comunidad geocientífica, que resida en servidores externos a la revista y ofrezca datos geoespaciales y mapas a través de conexiones OGC.

Cada uno de estos productos consta por lo menos de dos componentes: a) un artículo corto en español o en inglés, en el que se justifique el aporte científico/metodológico del mapa, colección de datos o servicios de información. b) El mapa "impreso" mismo -o su equivalente digital. En el caso de los productos 2 a 5, los datos espaciales subyacentes incluyendo: el documento digital del mapa ${ }^{3}$, todas las capas a las que hace referencia, el metadato espacial de las capas relevantes, los archivos de especificación de estilo de cada una de las capas y, opcionalmente, contenidos multimedia y/o ligas a servicios de información OGC. Para las colecciones de datos se solicitará por lo menos un mapa sencillo que muestre la densidad, distribución y cobertura de los datos. En el caso particular de las reseñas de servicios no se solicitan los datos sino los enlaces OGC los mapas y/o servicios de datos correspondientes.

En cuanto a los procesos editoriales adicionales: la calidad y relevancia científica del mapa imprimible y el texto que lo acompaña deberá evaluarla el comité científico. Al editor de cibercartografía le tocara evaluar la calidad del mapa, de los datos espaciales subyacentes y su aptitud para ser publicado como producto Web interactivo. El equipo de programación generará el código del mapa Web según el tipo de publicación. También le corresponde generar el código para integrar el texto y las galeras de mapa. De esta manera, a partir de los roles y procesos normales de OJS (figura 1), sería necesario añadir los siguientes procesos y roles para la publicación de productos cibercartográficos (figura 2):

1) Proceso de envío: El autor envía un mapa digital y el artículo asociado. Puede proponer uno (o más) tipo(s) de publicación para el mapa.

2) Proceso de revisión: Una vez que los que los revisores científicos determinan que el envío es relevante y pertinente inicia la revisión cartográfica.

a) El autor captura el metadato de su mapa

b) Captura el metadato de las capas relevantes 
Osorno Covarrubia, J., Couturier S., López Quiroz P., Ferrari L., Martínez Zazueta, I., (2018):Terra Digitalis: diseño e implementación de una revista internacional interactiva de mapas arbitrados", GeoFocus (Artículos), $n^{\circ} 22$, p. 115-139. ISSN: 1578-5157 http://dx.doi.org/10.21138/GF.555

c) El editor de cartografía juzga la calidad semántica y semiótica del mapa de acuerdo con las convenciones en el ramo de las geociencias pertinente, y en su caso emite recomendaciones

d) El editor de cartografía Web asigna la revisión de los archivos espaciales (y multimedia en caso de que existan) para detectar problemas de compatibilidad y proponer soluciones.

3) Proceso de edición: El corrector de cartografía Web resuelve los problemas de compatibilidad, formato y estilo.

a) El programador genera el visualizador para el mapa estático y los visualizadores adicionales

b) El revisor de cartografía corrige los errores de estilo.

c) El revisor de cartografía web realiza una revisión final de los mecanismos de interacción en cada mapa para detectar y corregir errores de programación.

4) Integración de sistemas: El programador integra todas las galeras de texto, las galeras de mapa y servicios de información geográfica pertinentes para el número.

5) Publicación de mapas y servicios: El administrador de la IDE publica los servicios y mapas.

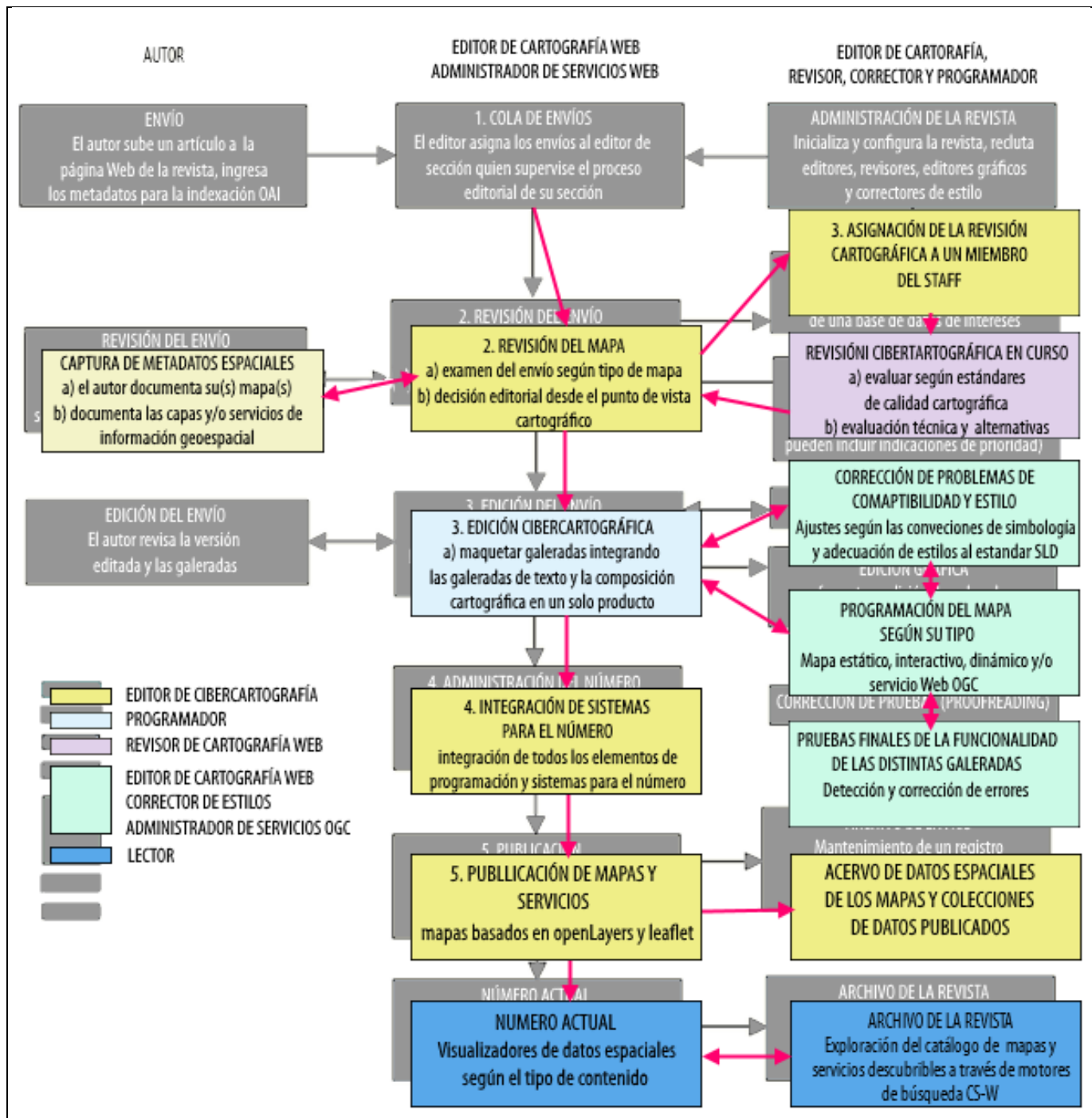

Figura 2. Procesos adicionales para la evaluación, edición y publicación de productos cibercartográficos. 


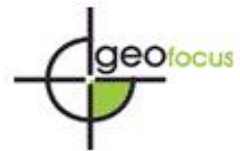

Osorno Covarrubia, J., Couturier S., López Quiroz P., Ferrari L., Martínez Zazueta, I., (2018):Terra Digitalis: diseño e implementación de una revista internacional interactiva de mapas arbitrados", GeoFocus (Artículos), $n^{\circ} 22$, p. 115-139. ISSN: 1578-5157 http://dx.doi.org/10.21138/GF.555

2.2. Limitaciones del OJS y de la revista internacional Journal of Maps

\subsubsection{Visualización de mapas}

Para la visualización de mapas, el Journal of Maps utiliza las funcionalidades de los navegadores normales de Internet (Chrome, Firefox, Internet Explorer, Edge, etc.) que proveen de herramientas simples para visualizar archivos PDF. Estas herramientas presentan las siguientes limitaciones comunes para examinar documentos cartográficos de alta resolución (Brus et al., 2015):

- La carga de archivos PDF de alta resolución es muy lenta.

- Zoom in/out centrado en la esquina superior izquierda y no en la posición del cursor.

- Desplazamiento lateral horizontal y vertical por separado.

- En el navegador "Google Chrome" por ejemplo, la barra de herramientas emerge al acercar el cursor a la esquina inferior derecha, lo cual resulta poco intuitivo y difícil de descubrir para cualquier usuario no habituado (figura 3).

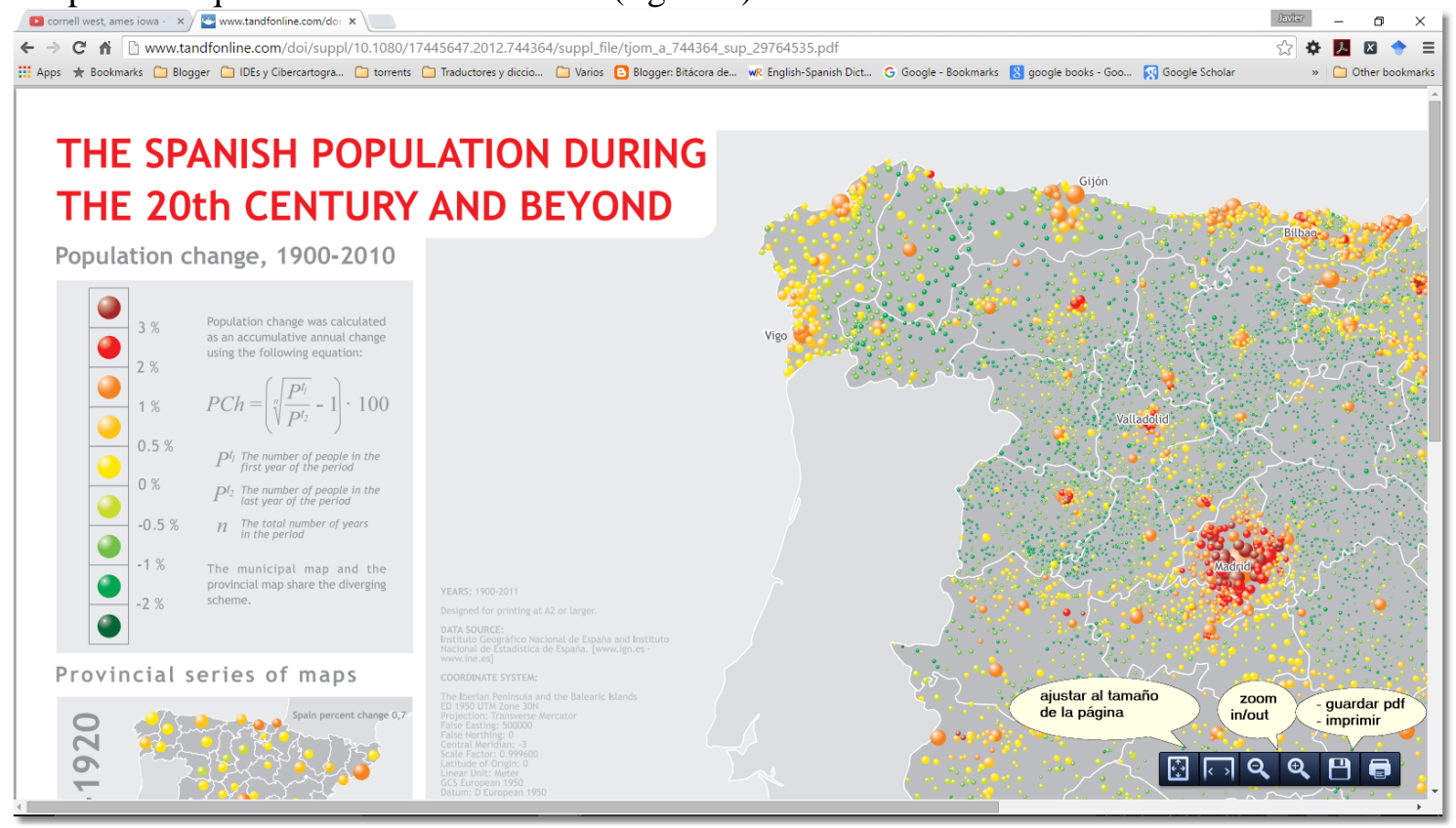

Figura 3. Examen de un PDF muy grande obtenido en el "Journal of Maps" como ejemplo que ilustra las limitaciones de los navegadores para el examen de documentos cartográficos de alta calidad. Se añaden letreros encima de la barra de herramientas emergente que describen su función.

- En Microsoft Edge (el explorador de Windows 10), la herramienta de zoom está "oculta" en el menú de opciones (figura 4)

- El mapa es estático en el sentido de que no se puede cambiar de escala ni encender o apagar capas. De hecho, la información no se organiza en capas pese a que los datos fuentes si tienen presenten esa estructura

- Solo se puede explorar una página a la vez, a menos que se abran dos instancias del navegador puestas en mosaico, por lo tanto, para el lector común es difícil revisar al mismo tiempo, el texto del artículo y el mapa

- No es posible examinar en el mapa contenidos multimedia georreferenciados como fotografías, secuencias de mapas animadas, ni contenidos de audio y video. 
Osorno Covarrubia, J., Couturier S., López Quiroz P., Ferrari L., Martínez Zazueta, I., (2018):Terra Digitalis: diseño e implementación de una revista internacional interactiva de mapas arbitrados", GeoFocus (Artículos), $n^{\circ} 22$, p. 115-139. ISSN: 1578-5157 http://dx.doi.org/10.21138/GF.555

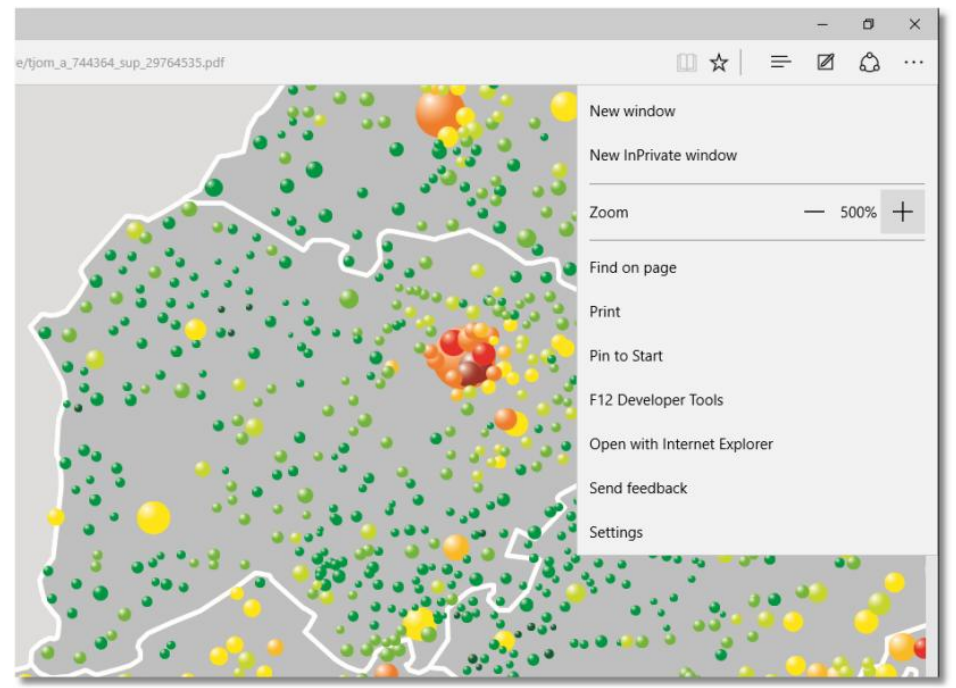

Figura 4. Menú de herramientas "oculto" en el navegador Microsoft Edge

En la revista de mapas arbitrados "Journal of Maps", los mapas de alta resolución se registran y almacenan como "archivos suplementarios" optativos.

\subsubsection{Visualización de textos en OJS y el "Journal of Maps"}

El texto se examina en un visualizador de PDFs separado similar al que se utiliza en OJS (figura 5)(ver Weaver, 2007) y la visualización de mapas ocurre a través del mecanismo por omisión del navegador Web (figuras 3 y 4).

En OJS es posible configurar como plugin el visualizador "PDF js viewer" (figura 5).

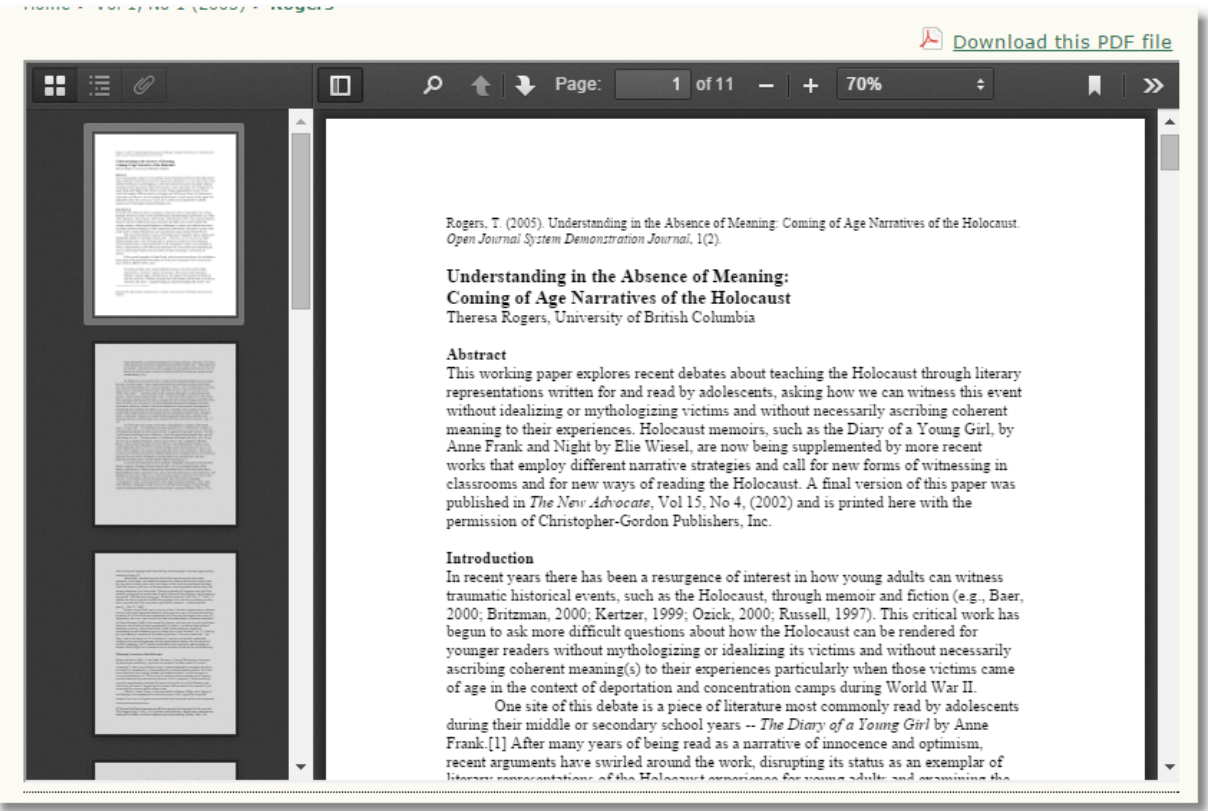

Figura 5. Visualizador de artículos en formato PDF con Pdf Js viewer 
Osorno Covarrubia, J., Couturier S., López Quiroz P., Ferrari L., Martínez Zazueta, I., (2018):Terra Digitalis: diseño e implementación de una revista internacional interactiva de mapas arbitrados", GeoFocus (Artículos), $n^{\circ} 22$, p. 115-139. ISSN: 1578-5157 http://dx.doi.org/10.21138/GF.555

Esta herramienta presenta algunas mejoras respecto a los visualizadores por omisión como las siguientes:

- Barra de miniaturas (thumbnails)

- Tabla de contenido

- Posibilidad de ir directamente a una página específica

- Herramientas de búsqueda

Sin embargo, si se utiliza esta herramienta para la visualización conjunta del texto y mapas de alta resolución, se presentan las limitaciones de navegación referidas arriba.

2.2.3 Extensiones existentes en OJS para la publicación de contenidos multimedia

Aparte de la publicación de documentos de texto --o de texto con imágenes, OJS también contempla la publicación de otros tipos de contenidos, como se ilustra en la figura 6.

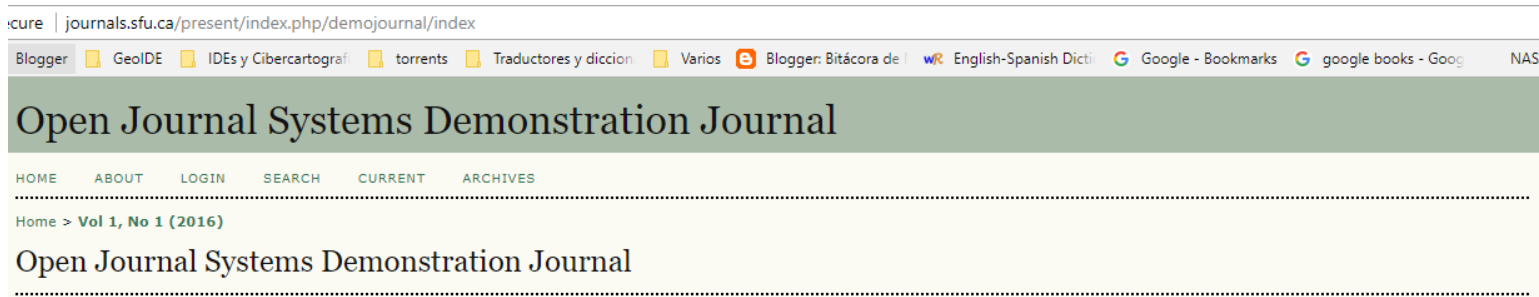

\begin{tabular}{|c|c|}
\hline \multicolumn{2}{|l|}{ Table of Contents } \\
\hline Multimedia & \\
\hline $\begin{array}{l}\text { Open for What? Open to What? Beyond Content } \\
\text { John Willinsky }\end{array}$ & VIOEE \\
\hline$\frac{\text { Sneak Peek at ols } 3.0}{\text { Kevin Stranack }}$ & SLOES \\
\hline \multicolumn{2}{|l|}{ Articles } \\
\hline $\begin{array}{l}\text { Understanding in the Absence of Meaning: Coming of Age Narratives of the Holocaust } \\
\text { Theresa Rogers }\end{array}$ & HTML POF \\
\hline $\begin{array}{l}\text { Inverted Hollywood: The Pitch for e-Knowledge } \\
\text { Lisa Korteweg }\end{array}$ & HTML D.F \\
\hline 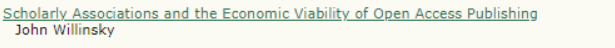 & HTML POF \\
\hline $\begin{array}{l}\text { Copyright Contradictions in Scholarly Publishing } \\
\text { John Willinsky }\end{array}$ & HTML D. Dof \\
\hline $\begin{array}{l}\text { "Are they talking yet?" Online Discourse as Political Action } \\
\text { Shula Klinger }\end{array}$ & HTM D. D.F \\
\hline $\begin{array}{l}\text { Democracy and Education: The Missing Link May Be Ours } \\
\text { John Willinsky }\end{array}$ & HTML POF \\
\hline
\end{tabular}

Figura 6. Publicación en OJS de contenidos de texto y contenidos multimedia (video, slides y audio) a través de visualizadores. En el recuadro en rojo nótense los vínculos a "visualizadores" especializados (página de demostración de OJS (Public Knowledge Project, 2016)).

Los contenidos de audio y video pueden visualizarse dentro de la plataforma OJS a través de reproductores multimedia apropiados. Los contenidos de tipo presentación pueden manipularse embebiendo ligas a visualizadores externos como el visualizador "slide share". Los videos y animaciones pueden ejecutarse a través del reproductor "flash player". Esta flexibilidad nos permite extender la funcionalidad de OJS con los elementos que se examinan en la sección 4. 
Osorno Covarrubia, J., Couturier S., López Quiroz P., Ferrari L., Martínez Zazueta, I., (2018):Terra Digitalis: diseño e implementación de una revista internacional interactiva de mapas arbitrados", GeoFocus (Artículos), $n^{\circ} 22$, p. 115-139. ISSN: 1578-5157 http://dx.doi.org/10.21138/GF.555

\section{Estructura y organización de la revista Terra Digitalis}

\subsection{Objetivos, alcance y modalidades de publicación}

Terra Digitalis puede definirse como una revista interdisciplinaria, revisada por pares que tiene como objetivo proporcionar un foro para la publicación en línea de mapas científicos, junto con los datos y código subyacentes. En un sentido amplio, Terra Digitalis se ocupa de procesos naturales y antrópicos que tienen lugar a escala geográfica. Los temas podrían incluir, por ejemplo, mapas digitales con datos nuevos sobre: la dinámica de las placas tectónicas en una región dada, los procesos de subsidencia en una ciudad durante un lapso determinado, los cambios en el uso de suelo y vegetación en una región y periodo, el mapa multimedia de un nuevo geo-parque, o la reseña de un nuevo servicio de información en línea que publica mapas y datos provenientes de un nuevo sensor geoestacionario. El hilo conductor, en todo ello es el mapa, los datos georreferenciados y potencialmente el código subyacente.

El comité editorial de la revista estará integrado inicialmente por uno a tres miembros de los institutos promotores ${ }^{4}$, no obstante, como es una revista bilingüe (español e inglés) que se plantea alcanzar difusión internacional, buscará integrar en él a autoridades científicas de otras instituciones y países.

Los mapas o colecciones digitales presentados deben hacer una contribución sustancial al conocimiento en su campo y deben aportar datos nuevos o adiciones significativas al valor de datos existentes. Las reseñas de servicios pueden solicitarse por invitación o ser enviadas por motu-proprio, y las realizaría alguien involucrado en el diseño, implementación y operación del mismo. Estas también serán revisadas por pares.

Debe notarse que, desde un punto de vista técnico, las modalidades de publicación definidas en la sección 2.1 --mapa estático, dinámico, interactivo, 3D, colección de datos y reseña de servicio; no se excluyen entre sí, sin embargo, cada forma adicional consume tiempo y recursos de manera que el autor en acuerdo con el editor debe elegir la(s) modalidad(es) tomando en cuenta la naturaleza de la información y la pertinencia y complementariedad de las formas adicionales (tabla 1).

Tabla 1. Ejemplo hipotético de modos de publicación para los artículos de un número de la revista. Nótese que: 1) todos los mapas tienen que ir acompañados de un artículo corto;2) debe de existir al menos una variante de mapa digital y 3) el mapa puede publicarse en varias modalidades

\begin{tabular}{|c|c|c|c|c|c|c|c|c|}
\hline & \multirow{2}{*}{$\begin{array}{l}\text { Editor de sección } \\
\text { encargado/tema general }\end{array}$} & \multicolumn{7}{|c|}{ Tipo de mapa (o publicación) } \\
\hline & & $\begin{array}{l}\text { Artículo } \\
\text { corto }\end{array}$ & Estático & Interactivo & Dinámico & $3 \mathrm{D}$ & $\begin{array}{l}\text { Colección de } \\
\text { datos }\end{array}$ & $\begin{array}{c}\text { Reseña de } \\
\text { servicios OGC }\end{array}$ \\
\hline Publicación 1 & Geofísica/tectónica de placas & $\checkmark$ & & $\checkmark$ & & & & \\
\hline Publicación 3 & Geografía/redes de transporte & $\checkmark$ & $\checkmark$ & & & & $\checkmark$ & $\checkmark$ \\
\hline Publicación 4 & $\begin{array}{c}\text { Geografía } \\
\text { Ambiental/vegetación }\end{array}$ & $\checkmark$ & & $\checkmark$ & & $\checkmark$ & & \\
\hline Publicación 5 & $\begin{array}{l}\text { Ciencias de la } \\
\text { tierra/subsidencia }\end{array}$ & $\checkmark$ & & & $\checkmark$ & & & \\
\hline
\end{tabular}

En el caso de las colecciones de datos se pide al menos un mapa sencillo, que muestre la extensión, ubicación y densidad de los datos colectados. Para los servicios Web se piden, de los enlaces OGC, con ejemplos ilustrativos de los mapas y/o colecciones de datos disponibles. 
Osorno Covarrubia, J., Couturier S., López Quiroz P., Ferrari L., Martínez Zazueta, I., (2018):Terra Digitalis: diseño e implementación de una revista internacional interactiva de mapas arbitrados", GeoFocus (Artículos), $n^{\circ} 22$, p. 115-139. ISSN: 1578-5157 http://dx.doi.org/10.21138/GF.555

3.2 Organización del flujo de procesos para atender las tareas de cibercartografía

Los aspectos de cartografía Web que se implementan en nuestra revista, con su potencial dinámico y de acceso a los datos subyacentes, la distinguen de cualquier otra y esto debe destacarse apropiadamente. Implican la realización de tareas relacionadas con la administración de sistemas, la edición y programación de cartografía Web (estática e interactiva) y la administración de servicios de información geográfica en línea (ver tabla 2).

Tabla 2. Roles tradicionales y roles análogos nuevos para una revista cibercartográfica

\begin{tabular}{|l|l|}
\hline Roles en una revista científica tradicional & $\begin{array}{l}\text { Roles análogos propuestos en una revista } \\
\text { de cartografía Web interactiva }\end{array}$ \\
\hline Eestor de la revista & $\begin{array}{l}\text { Administrador de datos espaciales y servicios } \\
\text { de información geográfica en línea }\end{array}$ \\
\hline $\begin{array}{l}\text { Editor de sección (geología, geofísica, } \\
\text { ciencias de la atmósfera, geografía, etc.) }\end{array}$ & \begin{tabular}{l} 
Editor de cibercartografía \\
\hline Revisor por sección
\end{tabular} \\
\hline Revisor de estilo & $\begin{array}{l}\text { Revisor de datos para de cartografía por sección (geología, } \\
\text { geofísica, etc.) }\end{array}$ \\
\hline Maquetador, corrector de estilo & $\begin{array}{l}\text { "Corrector de estilo" (y/o programador) por } \\
\text { tipo de contenido (mapa Web estático, } \\
\text { interactivo mapa, dinámico y/o servicio de } \\
\text { información en línea) }\end{array}$ \\
\hline Corrector de pruebas (proofreader) & Revisor final del producto web interactivo \\
\hline
\end{tabular}

El equipo de programación que cubre estos roles nuevos no solo tiene importancia decisiva al principio, al establecer la arquitectura del sistema, su diseño y posibilidades funcionales, sino que también jugará un rol importante en cada número realizando los procesos necesarios para llevar un producto arbitrado del mapa digital fuente al mapa Web interactivo,. Las destrezas de este de este equipo se centran en la programación, la gestión de sistemas y la tecnología SIG. Por esta razón proponemos crear un rol de "editor de cibercartografía", "administrador" de "sistemas y servicios de información geográfica en línea" y los roles complementarios de revisión, edición y programación de productos web interactivos.

\subsection{Casos de uso del sistema}

Como se propone en la figura 7, los roles y formas de uso del sistema pueden agruparse en actores externos -autores y lectores, el comité científico (integrado por el editor en jefe, los editores de sección y los revisores), administradores (de la revista y de la infraestructura de datos subyacente), y el equipo de edición (revisores y correctores de estilo, maquetadores, revisores, editores y programadores de cartografía web). 


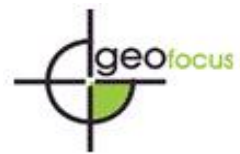

Osorno Covarrubia, J., Couturier S., López Quiroz P., Ferrari L., Martínez Zazueta, I., (2018):Terra Digitalis: diseño e implementación de una revista internacional interactiva de mapas arbitrados", GeoFocus (Artículos), $n^{\circ} 22$, p. 115-139. ISSN: 1578-5157 http://dx.doi.org/10.21138/GF.555

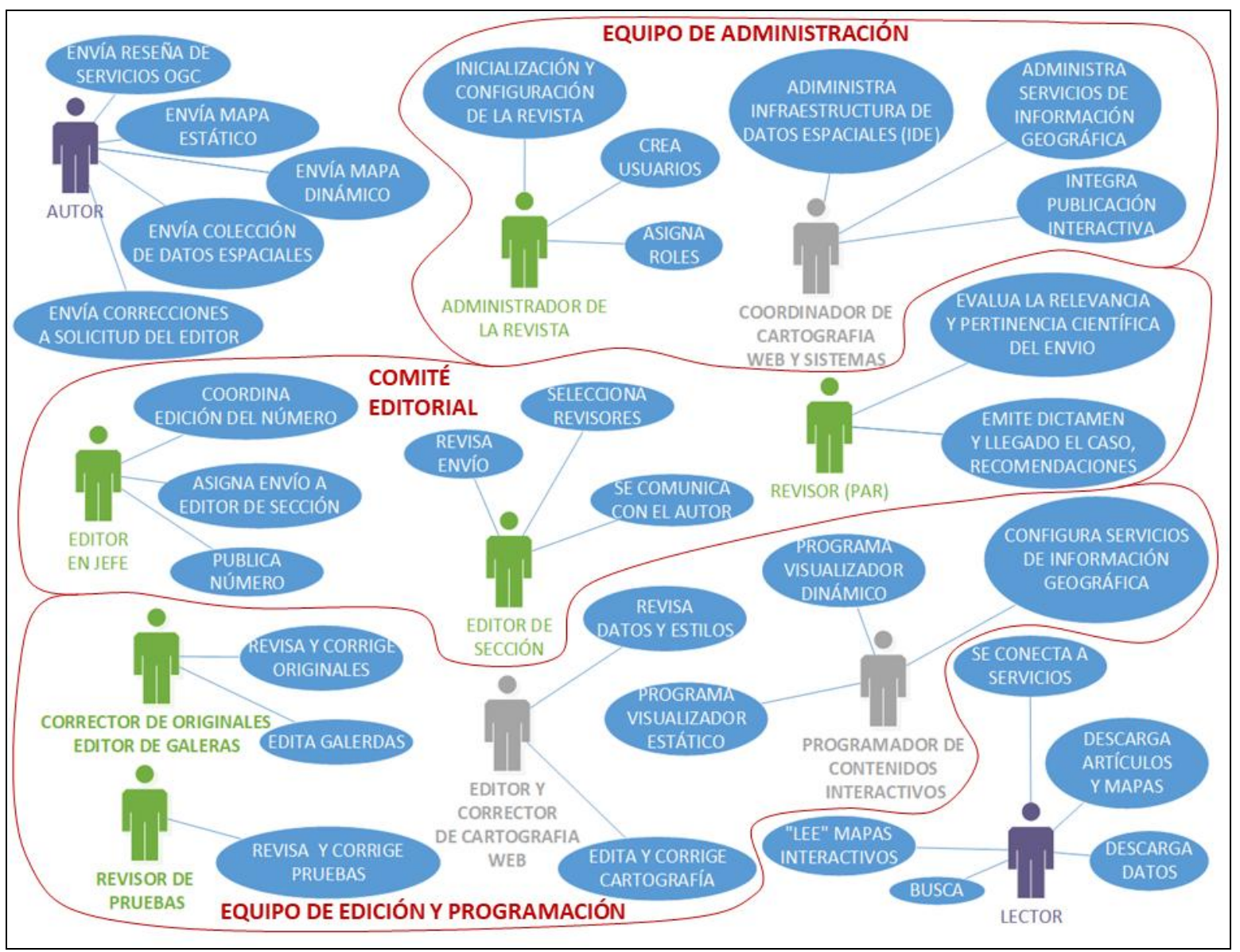

Figura 7. Vista agregada de los casos de uso del sistema. Se destacan en gris los roles relacionados con la edición y programación de productos cibercartográficos y la gestión de la infraestructura de datos subyacentes.

La tabla 3 examina el caso de uso del sistema "enviar mapa" y sus variantes.

\section{Tabla 3. El caso de uso "el autor envía mapa"}

\begin{tabular}{|c|c|}
\hline Caso de uso: & El autor somete un mapa a revisión por pares \\
\hline Objetivo: & $\begin{array}{l}\text { Ofrecer las herramientas para que el autor pueda someter un mapa } \\
\text { registrando los metadatos del envío. El sistema valida los } \\
\text { requerimientos básicos y registra el envío en cola de espera. }\end{array}$ \\
\hline Actores: & Autor, subsistema de registro de artículos. \\
\hline Precondiciones: & $\begin{array}{l}\text { El autor está registrado en el sistema y tiene un usuario, contraseña y } \\
\text { una dirección de correo válida. }\end{array}$ \\
\hline $\begin{array}{l}\text { Metas (condiciones } \\
\text { de finalización } \\
\text { exitosa) }\end{array}$ & $\begin{array}{l}\text { El registro apropiado de un envío que consta de un archivo principal y } \\
\text { uno o más archivos complementarios y sus metadatos correspondientes. } \\
\text { El número y tipo de archivos complementarios depende del tipo de } \\
\text { publicación. }\end{array}$ \\
\hline $\begin{array}{l}\text { Condiciones de } \\
\text { conclusión fallida: }\end{array}$ & $\begin{array}{l}\text { 1. Que el usuario interrumpa el proceso 2. Que no pueda cargar } \\
\text { archivos porque tienen un formato inapropiado. 3. Que no pueda cargar } \\
\text { archivos porque son demasiado grandes }\end{array}$ \\
\hline
\end{tabular}




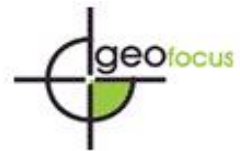

Osorno Covarrubia, J., Couturier S., López Quiroz P., Ferrari L., Martínez Zazueta, I., (2018):Terra Digitalis: diseño e implementación de una revista internacional interactiva de mapas arbitrados", GeoFocus (Artículos), $n^{\circ} 22$, p. 115-139. ISSN: 1578-5157 http://dx.doi.org/10.21138/GF.555

\section{Curso normal de eventos (mapa estático)}

Acciones del actor (el autor)

1. Revisa cada uno de los requisitos generales que debe cubrir para el envío. Si, a su juicio, cumple con los requisitos, continúa al siguiente paso.

2. Selecciona el tipo de publicación que quiere someter [mapa estático, mapa dinámico, colección de datos, reseña]. Selecciona el archivo principal de su envío en su disco duro y lo sube.

4. Captura los metadatos del envío (autores, título y resumen, referencias).

7. Carga un archivo adicional.

9. Captura los metadatos del archivo (título, creador, tipo de contenido \{materiales de investigación, análisis de datos, resultados de investigación, etc.\}, descripción breve). Si hay archivos adicionales regresa al paso 7 . Si no continúa al paso 10.

10. Confirma lista de archivos y confirma el envío.
Respuesta del sistema (el sistema)

3. Genera un nombre único, registra el nombre original, el tamaño y "time stamp" (fecha y hora) del envío.

5. Registra los metadatos del envío

6. presenta una dialogo para subir archivos según el tipo de envío seleccionado.

8. Despliega un dialogo para capturar metadatos de archivo complementario.

11. Registra el envío y lo introduce en la cola de espera.

Flujos alternativos (mapas interactivos, servicios o colecciones de datos)

En lugar de mapa estático el autor selecciona mapa interactivo (lo cual incluye las variantes, interactivo en 2D, interactivo en 3D y dinámico) (7.a), colección de datos (7.b) o reseña (7.c).

7.a El autor debe cargar un archivo de documento de mapa (.mxd, .lpk o .qgs) y las capas y especificaciones de estilo referidas en él. También puede especificar la extensión espacial de las capas, y las escalas máxima y mínima de visualización.

7.b El autor debe proveer un diccionario de datos y los archivos de la colección de datos a publicar.

7.c En este caso no hay archivos adicionales. La reseña incluye ligas OGC a los servicios de mapas reseñados. 8.a el sistema agrupa por mapa todos los archivos del envío, asignándoles un identificador jerárquico.

8.b. el sistema agrupa por colección todos los archivos del envío, asignándoles un identificador jerárquico.

\subsection{Diagrama de actividad del proceso editorial completo}

Proponemos un diagrama de actividad de una revista cibercartográfica arbitrada con su flujo de procesos (figura 8); El sistema recibe envíos y los pone en cola de espera. Para cada envío el editor selecciona un editor de sección. El editor de sección selecciona revisores. Los revisores evalúan el mérito científico del mapa y emiten un dictamen que puede ser: 1) aceptar el mapa para su publicación 2) aceptarlo con condiciones 3) rechazar la publicación. En el caso 2 el editor notifica al autor las modificaciones que tiene que realizar. Una vez satisfechas las 
Osorno Covarrubia, J., Couturier S., López Quiroz P., Ferrari L., Martínez Zazueta, I., (2018):Terra Digitalis: diseño e implementación de una revista internacional interactiva de mapas arbitrados", GeoFocus (Artículos), $n^{\circ} 22$, p. 115-139. ISSN: 1578-5157 http://dx.doi.org/10.21138/GF.555

condiciones, el caso uno y dos convergen. El editor de sección notifica al editor de cartografía Web para que evalúe el envío según el tipo de publicación solicitada. El editor Web revisa los datos sometidos y emite recomendaciones según el tipo de publicación. El mapa pasa a la fase de corrección de originales y edición que sigue dos vías: La de edición gráfica y la de programación Web. Una vez finalizadas las dos vías anteriores, el editor integra la publicación Web según el tipo de publicación. Este proceso se repite para cada envío hasta completar los artículos que integran el número (figura 8).

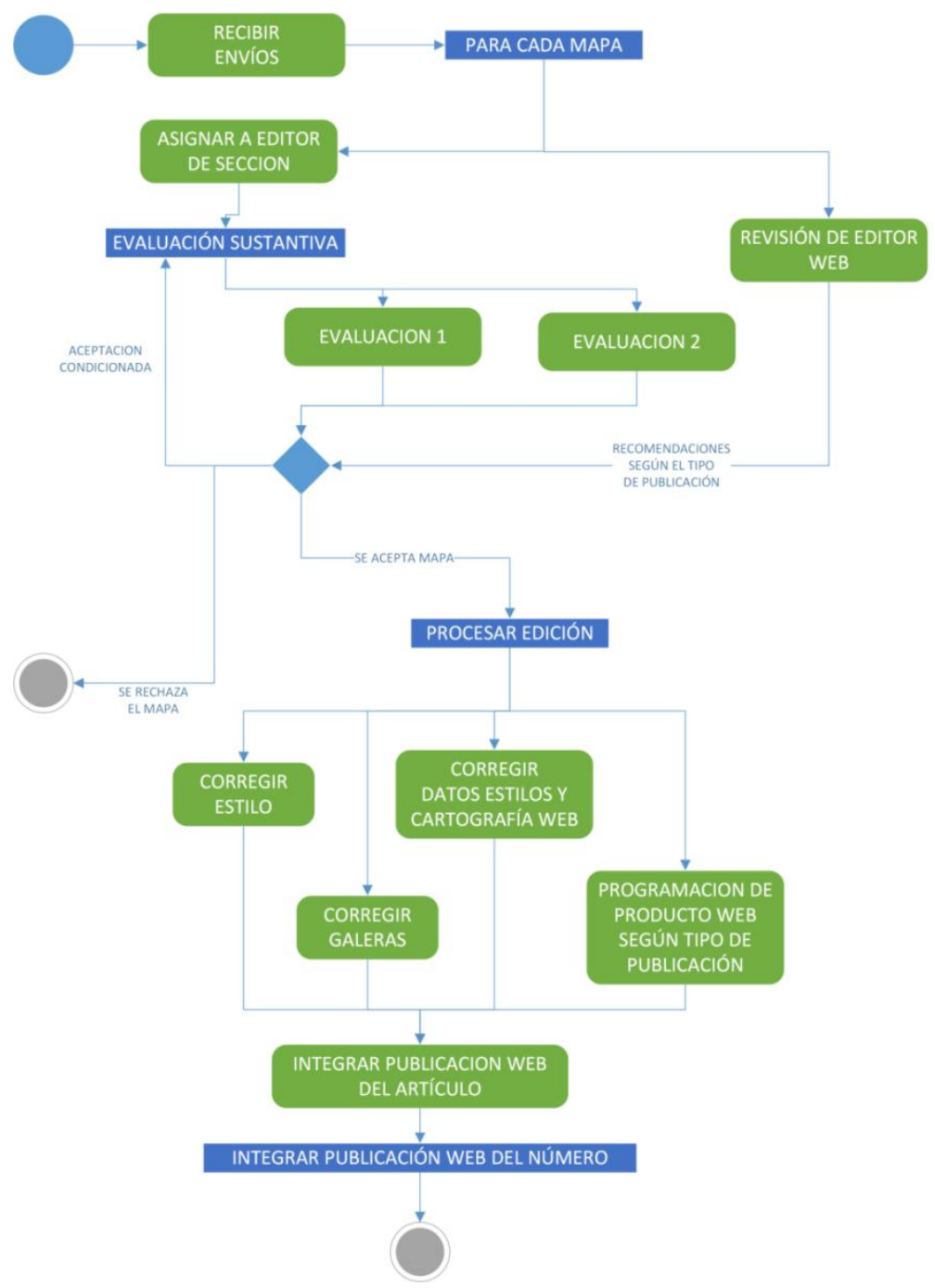

Figura 8. Flujo completo de procesos

3.5 Requerimientos de formato por tipo de producto

Los requerimientos generales de formato por tipo de producto son los siguientes:

1. Para mapas estáticos: archivo en formato PDF o PNG de alta resolución.

2. Para los mapas interactivos 2D:

- Documento de mapa: de preferencia en formato qgs (QGIS), puede ser también mxd o mpk (ArcGIS) 
Osorno Covarrubia, J., Couturier S., López Quiroz P., Ferrari L., Martínez Zazueta, I., (2018):Terra Digitalis: diseño e implementación de una revista internacional interactiva de mapas arbitrados", GeoFocus (Artículos), $n^{\circ} 22$, p. 115-139. ISSN: 1578-5157 http://dx.doi.org/10.21138/GF.555

- Conjunto de capas referenciadas en dicho documento: Estas pueden entregarse como bases de datos geoespaciales (de postgis o arcgis) o como conjuntos de $\operatorname{archivos}^{5}$ de preferencia en formatos shape o geotiff.

- Especificaciones de estilo de cada capa: de preferencia en formato sld; también puede ser en formato lyr.

3. Para mapas dinámicos: mismos requerimientos que los anteriores más las series de tiempo de la(s) capa(s) relevantes en formato vectorial o raster.

4. Para mapas 3D: mismos requerimientos que en el punto 2 más datos de elevación apropiados en formato raster.

5. Para colecciones de datos geoespaciales: se requiere a) un mapa sencillo que muestre la extensión, densidad y distribución de los datos colectados b) la colección de datos geoespaciales en formato tabular (tablas de postgis, base de datos geoespacial de ArcGIS, Excel, CSV) o shapefiles.

6. Para reseñas de servicios OGC existentes en servidores externos: las ligas a los servicios OGC.

En todos los casos se requiere un metadato espacial mínimo de mapa, y las capas y/o servicios más relevantes. El metadato puede capturarse, a posteriori, en el manejador de contenidos espaciales de la revista, o puede anexarse a cada capa como XML estructurado bajo el estándar ISO-TC211 ${ }^{6}$.

\subsection{Servicios Web residentes en nuestros servidores}

El sistema permitirá implementar servicios Web interoperables para los productos mapa interactivo y colecciones de datos (ver Mildorf et al., 2014) a través de servicios OGC: WMS (Web Map Services), WMTS (Web Map Tile Services), WFS (Web Feature Services), WCS (Web Coverage Services), y CS-W (Catalog Services for the Web).

La elección entre WMS y WFS toma en cuenta el tipo de acceso a los datos ofrecido por el autor. Si desea publicar un mapa interactivo pero no desea ofrecer sus datos de manera abierta, se elegirá un servicio WMS. Si el autor ofrece de manera abierta sus datos, el mapa se implementará como WFS o WCS (figura 10).

\section{Análisis de requerimientos y diseño de la interfaz de la revista Terra Digitalis}

4.1 Requerimientos para la visualización e interacción con datos espaciales

En concordancia con los objetivos de nuestra revista, nos planteamos la necesidad de implementar herramientas que no existen en OJS, bien adaptadas para la visualización de, e interacción con, cuatro tipos de contenido (ver Sluter et al., 2016):

1. Mapas estáticos de muy alta resolución en formatos grandes (A0, A1, A2 y A3) con orientación vertical o apaisada.

2. Contenidos multimedia como animaciones, videos y visualizaciones interactivas en 3D -asociados a todo el mapa o elementos específicos en él (Zhou et al., 2016).

3. Mapas interactivos que habiliten la interacción con los datos subyacentes; Por ejemplo apagar y encender capas, definir consultas, seleccionar capas o elementos dentro de una capa, examinar los datos de la capa seleccionada, ubicar en el mapa del objeto seleccionado en una tabla y viceversa, etc. 
Osorno Covarrubia, J., Couturier S., López Quiroz P., Ferrari L., Martínez Zazueta, I., (2018):Terra Digitalis: diseño e implementación de una revista internacional interactiva de mapas arbitrados", GeoFocus (Artículos), $n^{\circ} 22$, p. 115-139. ISSN: 1578-5157 http://dx.doi.org/10.21138/GF.555

4. Colecciones de datos espaciales e interacción a través de servicios OGC estandarizados para habilitar la descarga, consulta de metadatos y la conexión a servicios utilizando herramientas SIG especializados como QGIS, ArcGIS o Google Earth.

\subsection{Propuesta de visualizador multimedia bajo la metáfora de Atlas Interactivo}

La lectura de un mapa demanda a menudo el examen en paralelo de texto, gráficas, ilustraciones y leyendas y datos espaciales representados en el mapa, ordenados en forma harmónica y comunicativa. La forma probada de organizar todos estos elementos es a través de productos editoriales en formato de atlas. Bajo este paradigma el texto y las ilustraciones que describen el propósito del mapa, los métodos, el análisis de los resultados y las conclusiones, se alternan con los mapas que pueden ocupar páginas sencillas o dobles completas, utilizando hojas de tamaño mucho más grande que el tamaño utilizado normalmente para la publicación de texto.

El uso de herramientas de diseño y programación basadas en Action Script permite desarrollar interfaces visuales basadas en la metáfora de un atlas (Pucher, 2015). El documento se presentaría como un producto editorial "encuadernado" en hojas muy grandes, que consta de una página izquierda y una página derecha que pueden "pasarse" oprimiendo un botón o "arrastrando" el extremo de la hoja.

Así, proponemos una visualización acorde con la metáfora de Atlas Interactivo (figura 11); las especificaciones funcionales más significativas de la interfaz se presentan en la tabla 3.

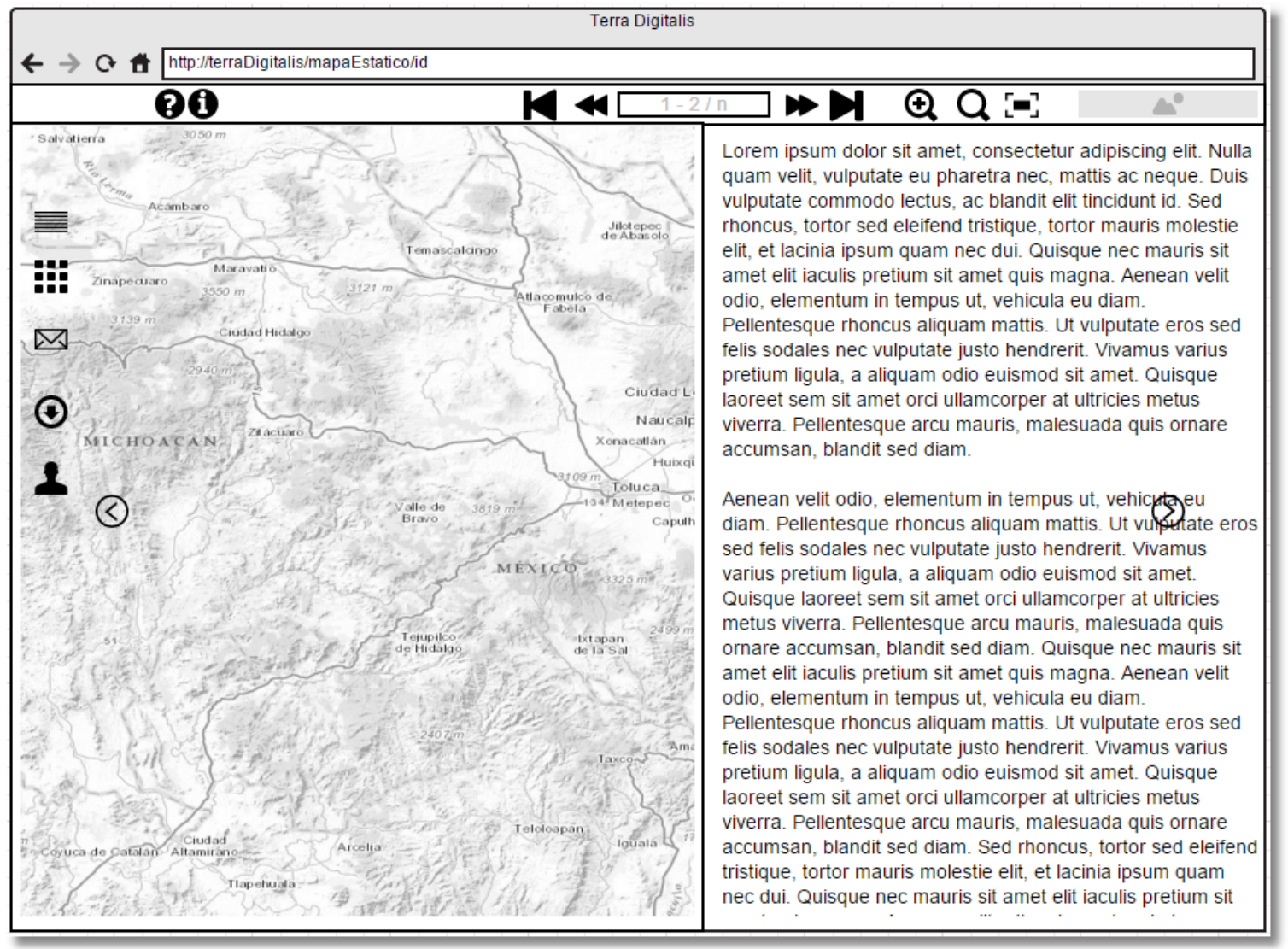

Figura 9. Propuesta de distribución de los elementos básicos de la interfaz del mapa estático. 


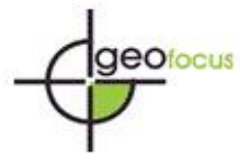

Osorno Covarrubia, J., Couturier S., López Quiroz P., Ferrari L., Martínez Zazueta, I., (2018):Terra Digitalis: diseño e implementación de una revista internacional interactiva de mapas arbitrados", GeoFocus (Artículos), $n^{\circ} 22$, p. 115-139. ISSN: 1578-5157 http://dx.doi.org/10.21138/GF.555

Tabla 4. Especificaciones funcionales más significativas de la figura 11.

\begin{tabular}{|l|l|}
\hline Requerimiento \\
Botón de ayuda: para activar una guía semitransparente sobre el uso de la \\
interfaz. \\
\hline $\begin{array}{l}\text { Botón de información: por ejemplo datos sobre el volumen y número de la } \\
\text { revista. }\end{array}$ \\
\hline $\begin{array}{l}\text { Navegación por página: permite moverse directamente a un par de páginas } \\
\text { específico. }\end{array}$ \\
\hline $\begin{array}{l}\text { Herramienta de zoom in/out centrada en el punto indicado por la posición } \\
\text { del cursor. }\end{array}$ \\
\hline Activar la búsqueda de texto en el artículo, el número o la revista. \\
\hline Activar el modo de pantalla completa. \\
\hline $\begin{array}{l}\text { Cambiar de página hacia adelante y hacia atrás. Otra forma natural de } \\
\text { cambiar de página es la de "arrastrar" la orilla de la misma en dirección } \\
\text { opuesta. }\end{array}$ \\
\hline Botones que expanden o colapsan paneles laterales semitransparentes. \\
\hline Tabla de contenido. \\
\hline Miniaturas (thumbnails). \\
\hline Compartir liga a través de redes sociales o correo electrónico. \\
\hline Descargar documento en PDF. \\
\hline Como citar el artículo. \\
\hline $\begin{array}{l}\text { Acceso (opcional) a la colección de datos asociada al mapa -en caso de } \\
\text { que exista. }\end{array}$ \\
\hline
\end{tabular}

Otros requerimientos deseables serían los siguientes:

- La carga del documento deberá de ocurrir con rapidez, incluso a través de conexiones lentas.

- La interfaz deberá admitir zooms muy altos para discernir todos elementos significativos del mapa, tipográficos y de simbología.

- Podrán incluirse elementos multimedia como animaciones, videos, gráficas y fotografías, activables por la interacción del usuario.

El diseño propuesto cubre los requerimientos (ver sección 2.1) de: 1) visualización eficiente de mapas de muy alta resolución en formatos grandes y 2) Integración opcional de contenidos multimedia.

4.3 Propuesta de visualizador de mapas interactivos

Para atender al requerimiento 3) (Mapas dinámicos que habilitan la interacción con los datos subyacentes) proponemos la interfaz descrita en la figura 12, con las especificaciones descritas en la tabla 4. 
Osorno Covarrubia, J., Couturier S., López Quiroz P., Ferrari L., Martínez Zazueta, I., (2018):Terra Digitalis: diseño e implementación de una revista internacional interactiva de mapas arbitrados", GeoFocus (Artículos), $n^{\circ} 22$, p. 115-139. ISSN: 1578-5157 http://dx.doi.org/10.21138/GF.555

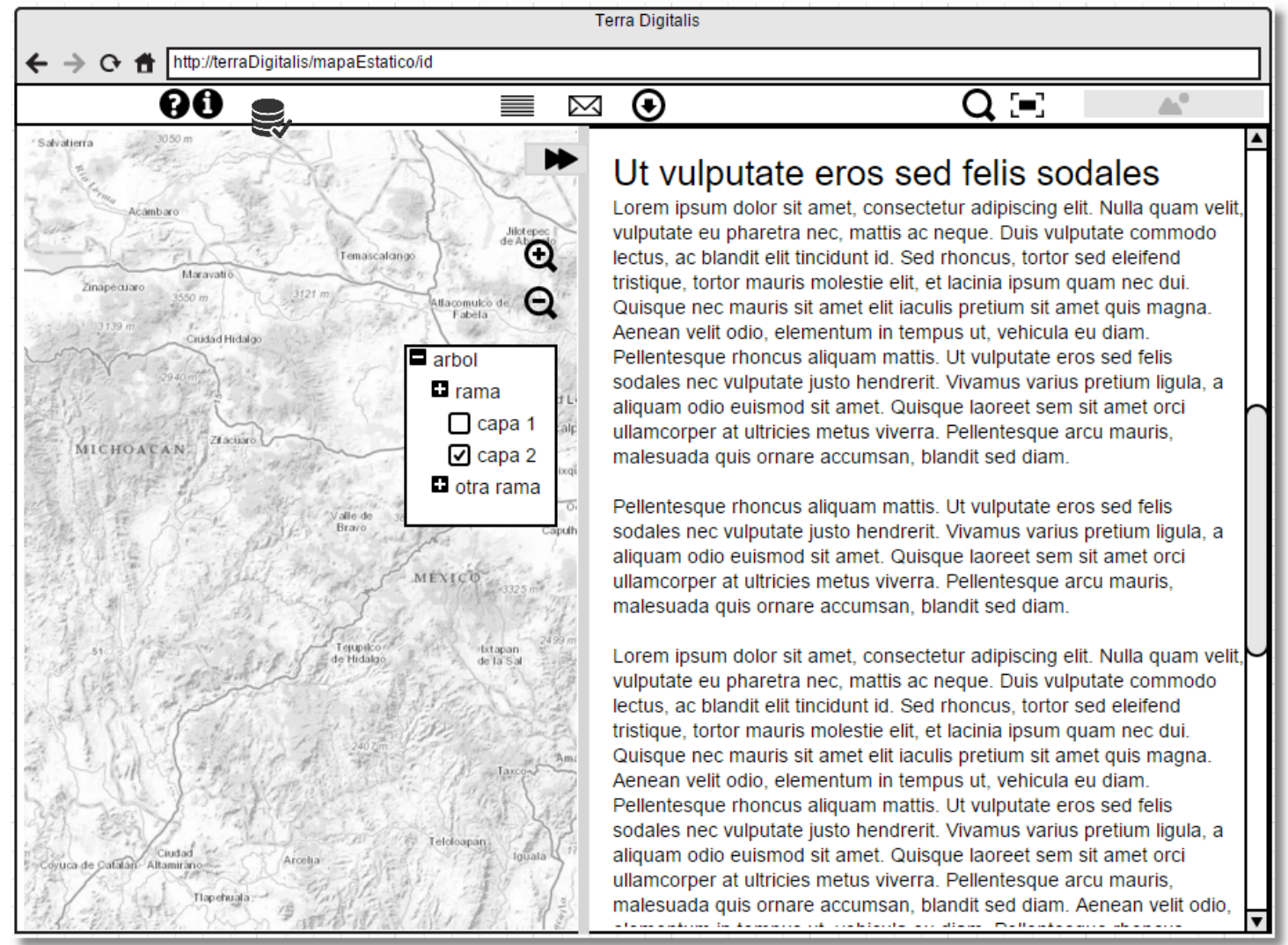

Figura 10. Propuesta de distribución de los elementos básicos del visualizador interactivo.

Tabla 5. Especificaciones para el visualizador interactivo.

\begin{tabular}{|c|c|}
\hline Requerimiento & Herramienta \\
\hline $\begin{array}{l}\text { En este visualizador, a diferencia del anterior, el mapa se construye de } \\
\text { manera dinámica a través de una conexión "viva" a un servicio de mapas } \\
\text { que responde a las peticiones que realiza el usuario a través de la interfaz. } \\
\text { Por esta razón el usuario puede encender o apagar capas (o grupos de capas) } \\
\text { y potencialmente realizar consultas, establecer filtros, seleccionar objetos y } \\
\text { examinar datos específicos. La interfaz es un documento html con dos } \\
\text { paneles dividido por una línea que se puede arrastrar o colapsar a la derecha } \\
\text { o a la izquierda para darle más espacio al mapa o al texto. En el panel de } \\
\text { texto (derecha), el texto está indexado para habilitar búsquedas. }\end{array}$ & $\begin{array}{l}\text { Ut } \\
\text { Lore }\end{array}$ \\
\hline $\begin{array}{l}\text { El control de capas permitirá mostrar la estructura jerárquica de la } \\
\text { información cartográfica y encender o apagar elementos. También habilitará } \\
\text { el cambio de capa base, que puede ser un servicio de imágenes de alta } \\
\text { resolución, como el de Google Earth o algún servicio cartográfico libre } \\
\text { como el de OpenStreetMap (OSM). Este mapa puede contener elementos } \\
\text { multimedia georreferenciados como gráficas, imágenes, fotos o videos }\end{array}$ & $\begin{array}{c}\text { - arbol } \\
\text { Ð rama } \\
\square \text { capa } 1 \\
\square \text { capa 2 } \\
\boldsymbol{\Phi} \text { otra rama }\end{array}$ \\
\hline
\end{tabular}


Osorno Covarrubia, J., Couturier S., López Quiroz P., Ferrari L., Martínez Zazueta, I., (2018):Terra Digitalis: diseño e implementación de una revista internacional interactiva de mapas arbitrados", GeoFocus (Artículos), $n^{\circ} 22$, p. 115-139. ISSN: 1578-5157 http://dx.doi.org/10.21138/GF.555

Las herramientas de zoom in / out permitirán cambiar la escala del mapa. Si el autor así lo desea, podrá especificar la visibilidad y la simbología de las capas a diferentes rangos de escala. Adicionalmente el autor puede establecer las escalas mínima, máxima y el recuadro dentro del cual pueden verse los datos (extent). El autor podrá seleccionar entre una variedad de mapas base o proveer uno él mismo.

Es deseable incluir herramientas de selección de objetos y visualización de los datos asociados. Esto permitiría examinar en la tabla los datos de un rasgo particular y/o buscar en el mapa la ubicación espacial de un rasgo seleccionado en la tabla. La tabla debería incluir herramientas de búsqueda de texto.

En esta interfaz el botón "descargar" permitirá obtener los datos fuente en formato shape, o kml. Esta última característica habilita el examen del mapa en Google Earth.

En caso de que el autor quiera publicar también los datos asociados al mapa a través de un servicio OGC, el botón "conectar a datos asociados" permitirá copiar el vínculo al servicio WMS o WFS y establecer una conexión remota desde una aplicación SIG como QGIS o ArcGIS Desktop (figura 8)

4.4 Habilitación de servicios OGC para colecciones de datos geo-científicos y reseñas de servicios

Una característica innovadora de nuestra revista, quizás útil para fomentar la validación de resultados e incrementar el número de citas a la revista, es la de ofrecer el acceso a colecciones de datos espaciales bajo dos modalidades. 1) Publicar los datos fuente asociados un mapa y 2) Publicar colecciones originales de datos geo-científicos. En este último caso se someterá a revisión por pares, un artículo breve que justifique la relevancia científica de los datos, los métodos de adquisición y un diccionario de datos para documentar la estructura de la base de datos (en caso de que aplique), las tablas, campos, tipos y dominios. Las colecciones de datos se indexarán en la revista y se ofrecerán como servicios WMS y WFS (figura 13).

Así mismo, agregamos la sección "Reseña de Servicios de información espacial en línea", dedicada al examen y descripción de contenidos de servicios de información relevantes para la comunidad geo-científica por ejemplo; servicios interoperables de imágenes satelitales de temperatura y color del océano, servicios de datos climatológicos, servicios de registros sísmicos actualizados en tiempo real (ver Fernández et al., 2017), etc. Se reseñaría la estructura, contenido y relevancia científica de estos recursos. Se publicarían los vínculos a servicios WMS, WFS, WCS y CS-W residentes en servidores externos. 


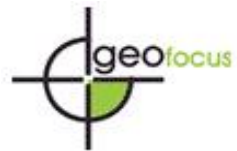

Osorno Covarrubia, J., Couturier S., López Quiroz P., Ferrari L., Martínez Zazueta, I., (2018):Terra Digitalis: diseño e implementación de una revista internacional interactiva de mapas arbitrados", GeoFocus (Artículos), $n^{\circ} 22$, p. 115-139. ISSN: 1578-5157 http://dx.doi.org/10.21138/GF.555

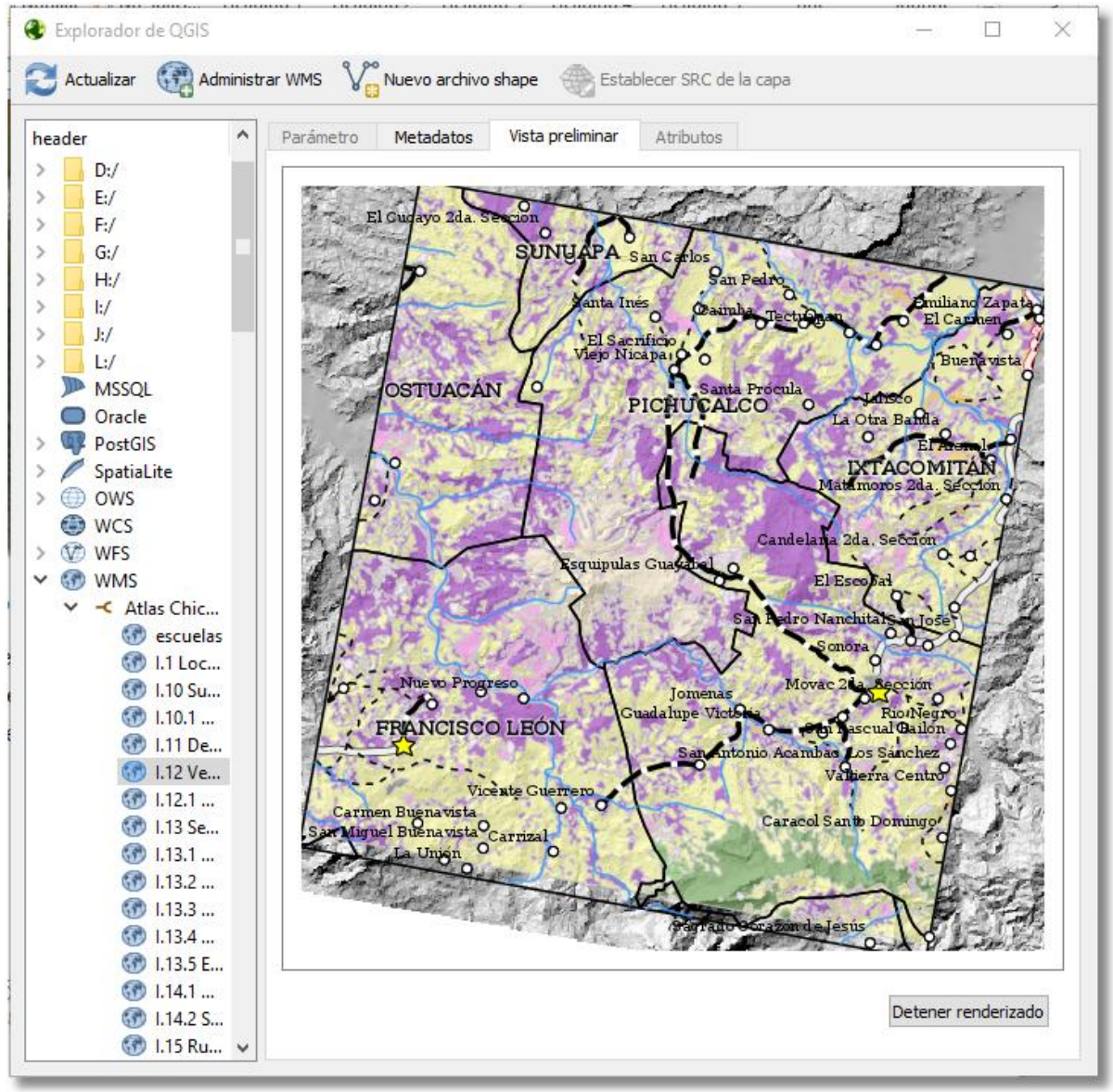

Figura 11. Ejemplo de conexión a un mapa publicado a través de una conexión OGC desde una herramienta SIG (en este caso una conexión WMS desde el explorador de QGIS).

\subsection{Arquitectura del sistema}

La gestión del proceso editorial se basará en el sistema OJS que opera sobre apache 2 y php. Para el manejo de los datos espaciales proponemos el uso de Geonode, que está optimizado para la gestión colaborativa de contenidos espaciales. Este sistema opera sobre Geoserver que permite administrar los servicios OGC. 
Osorno Covarrubia, J., Couturier S., López Quiroz P., Ferrari L., Martínez Zazueta, I., (2018):Terra Digitalis: diseño e implementación de una revista internacional interactiva de mapas arbitrados", GeoFocus (Artículos), $n^{\circ} 22$, p. 115-139. ISSN: 1578-5157 http://dx.doi.org/10.21138/GF.555

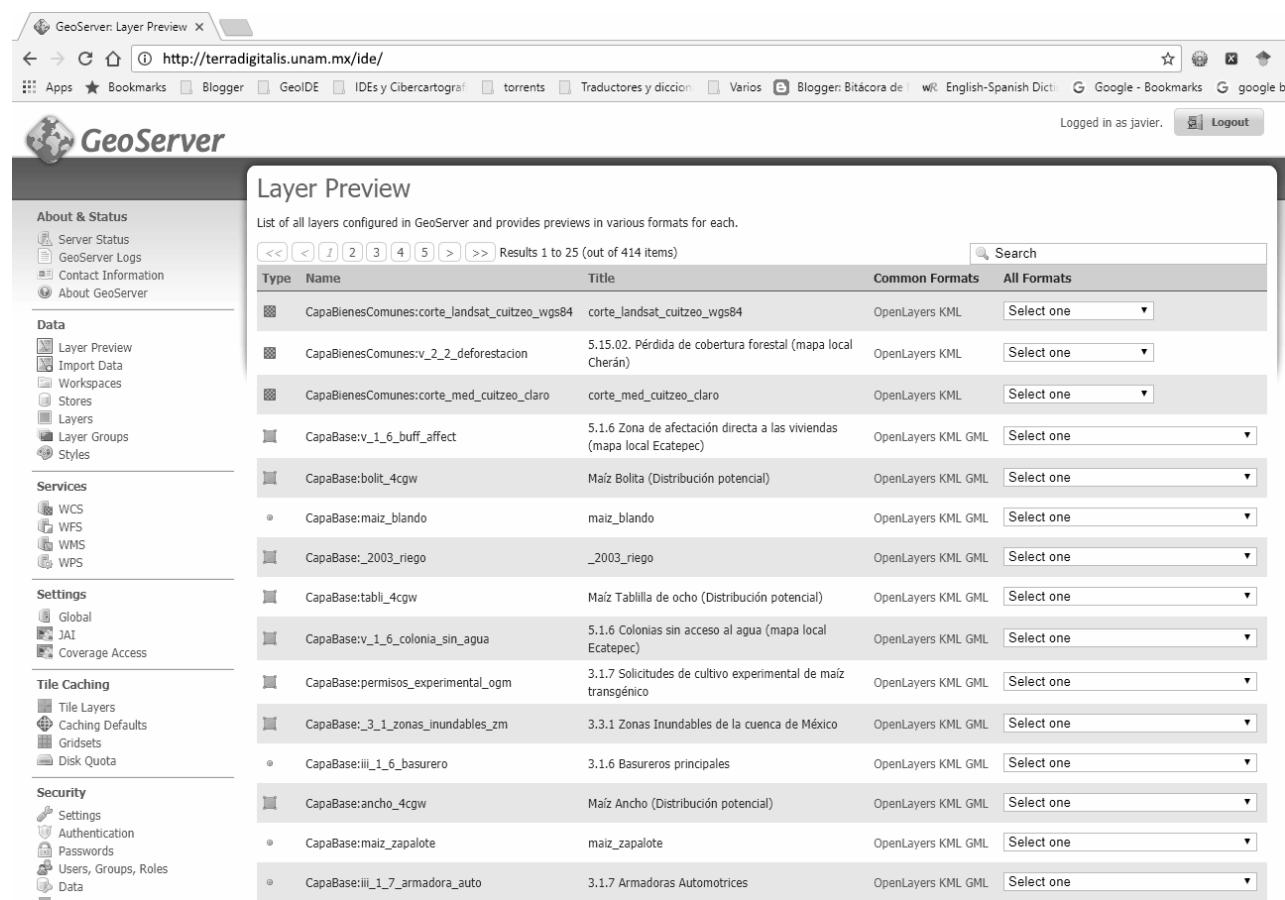

Figura 12. Ejemplo de pantalla de administración de servicios Web desde Geoserver

Los mapas interactivos se desarrollarán por medio de objetos OpenLeyers o leaflet, embebidos en cada artículo correspondiente a través de código en PHP. Estos mapas consumen los servicios OGC subyacentes.

4.6 Tabla de contenido de la revista

A partir del portal principal de la revista se podrá navegar entre artículos a través de la tabla de contenido del número (figura 13).

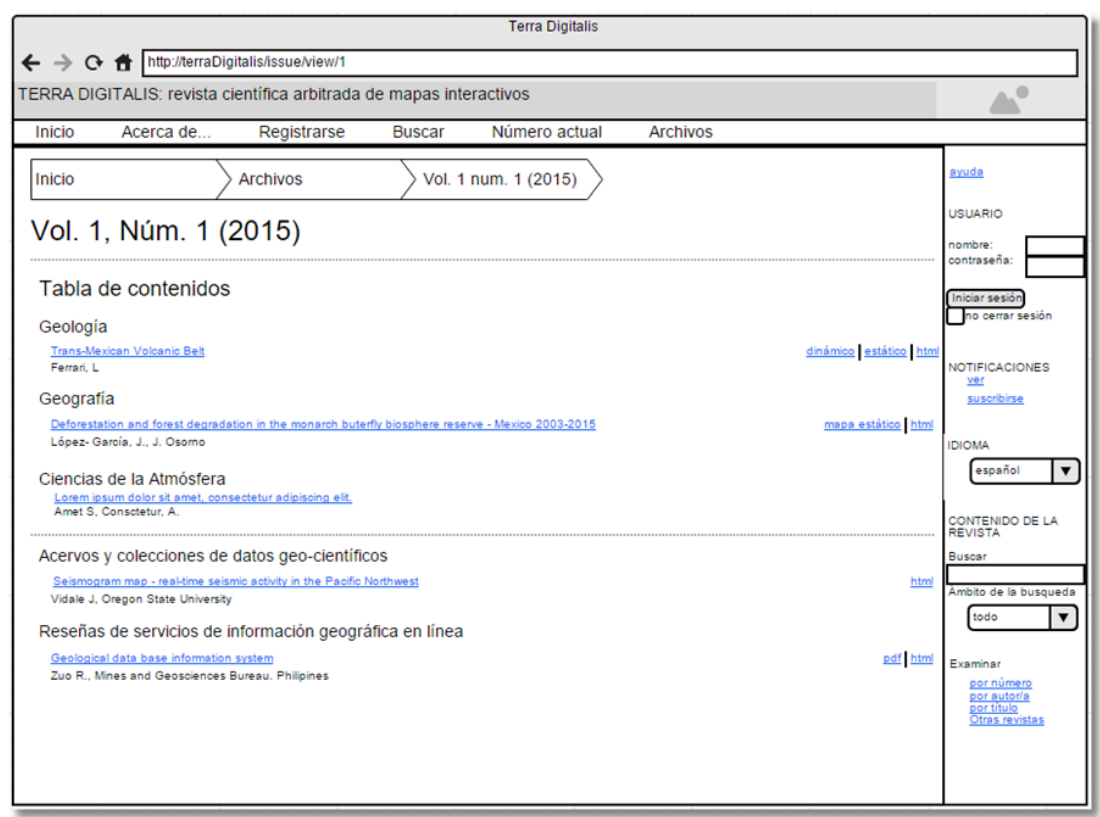

Figura 13. Propuesta de distribución de elementos de la tabla de contenido. Nótense a la derecha los enlaces, a los diferentes visualizadores según el tipo de publicación 


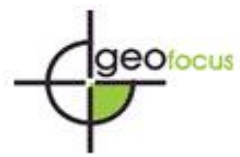

Osorno Covarrubia, J., Couturier S., López Quiroz P., Ferrari L., Martínez Zazueta, I., (2018):Terra Digitalis: diseño e implementación de una revista internacional interactiva de mapas arbitrados", GeoFocus (Artículos), $n^{\circ} 22$, p. 115-139. ISSN: 1578-5157 http://dx.doi.org/10.21138/GF.555

\section{Implementación del sistema: Visualizadores preliminares de la revista}

Se ofrecen tres visualizadores en la revista, dependiendo de la modalidad de publicación elegida por el autor: 1) un visualizador de mapa y texto bajo la metáfora de Atlas interactivo (figura 14), 2) visualizador de mapa interactivo y texto con "ventana corrediza" (ver figura 15), y 3 ) visualizador de mapa dinámico (ver figura 16).

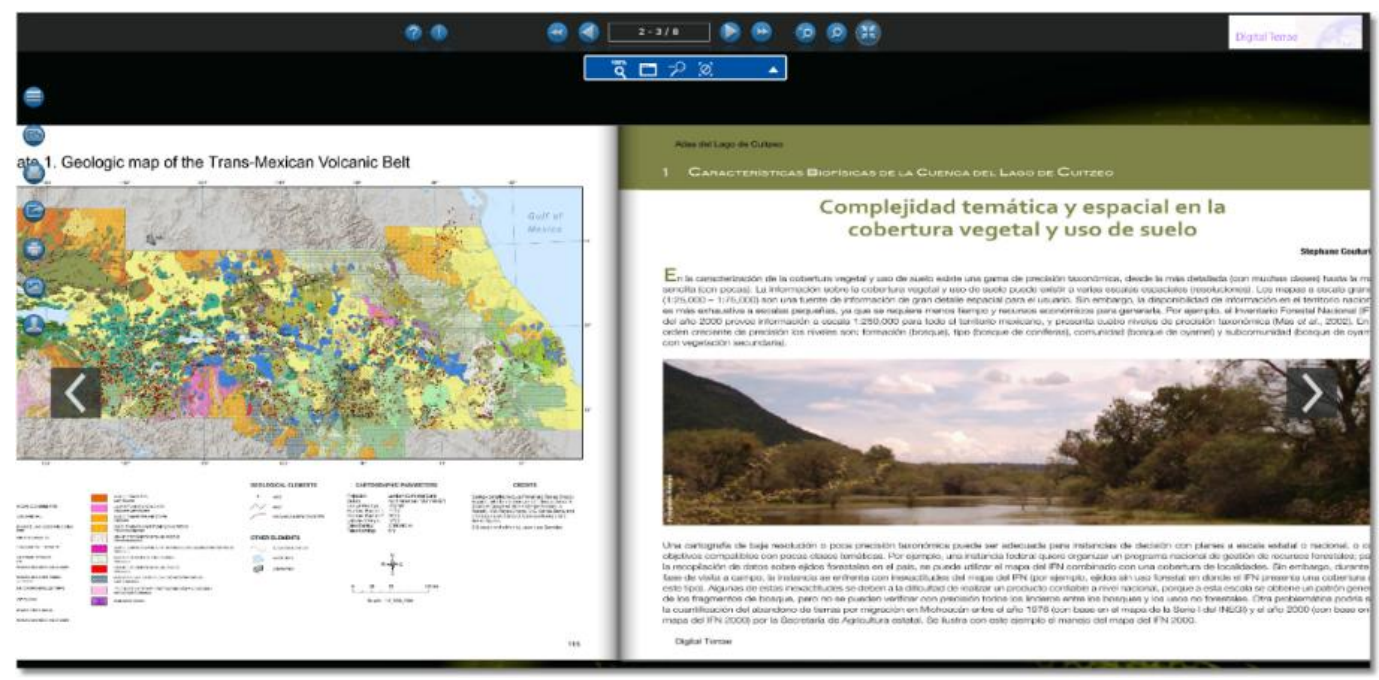

Figura 13. Visualizador de mapa y texto bajo la metáfora de atlas multimedia.
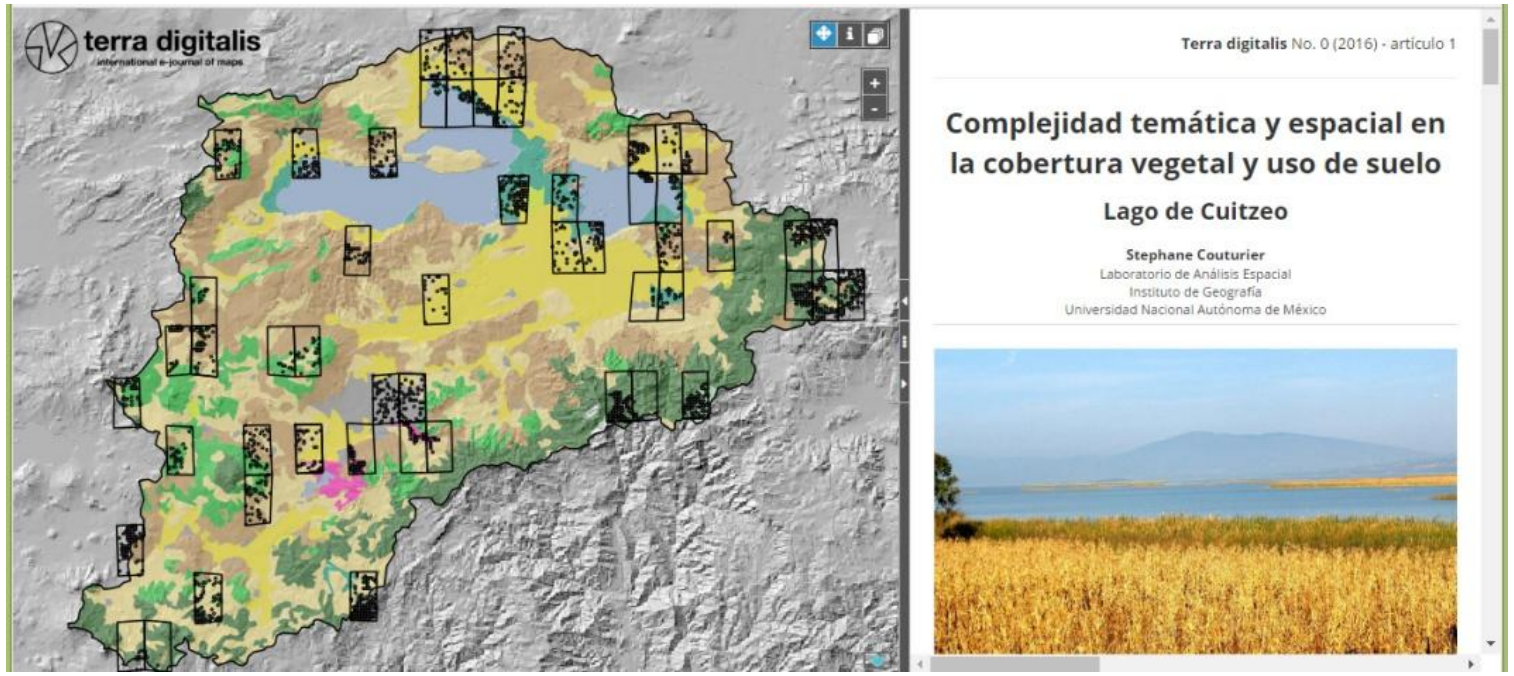

Figura 14. Visualizador de mapa interactivo con dos paneles en "ventana corrediza"

Conforme a los requerimientos señalados en este artículo, se logra la publicación de mapas interactivo de alta resolución (figura 17). También con esta interfaz se logra cumplir con el requerimiento de mapas interactivos que habiliten la interacción con los datos subyacentes como encender y apagar capas, seleccionar capas, solicitar información sobre las capas.

Con la publicación de mapas dinámicos tales como en la figura 18, se logra cumplir con el requerimiento secuencias de datos espacio temporales. 
Osorno Covarrubia, J., Couturier S., López Quiroz P., Ferrari L., Martínez Zazueta, I., (2018):Terra Digitalis: diseño e implementación de una revista internacional interactiva de mapas arbitrados", GeoFocus (Artículos), $n^{\circ} 22$, p. 115-139. ISSN: 1578-5157 http://dx.doi.org/10.21138/GF.555

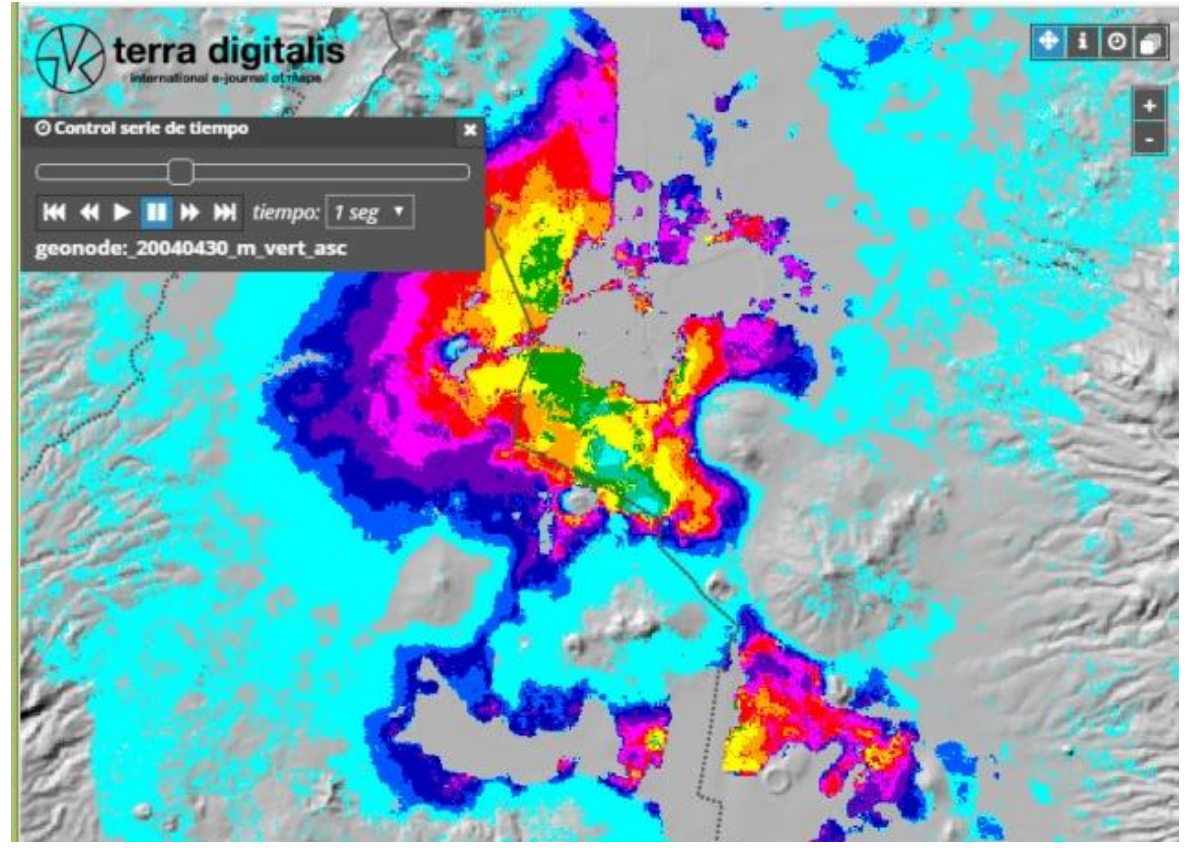

Figura 15. Visualizador interactivo de mapa dinámico (secuencia espacio-temporal).

En los tres tipos de mapa se pueden incluir contenidos multimedia georreferenciados

\section{Conclusiones}

En este artículo se presenta una iniciativa orientada a valorar el mapa como producto científico primario a través de la implementación de una revista arbitrada de mapas digitales interactivos. El análisis, por un lado, de la especificación de los requerimientos de calidad cartográfica, interactividad y administración de los datos geoespaciales, y por el otro, el examen de las capacidades funcionales de OJS para la gestión del proceso editorial, nos permitió establecer una arquitectura que extiende a este sistema para la publicación de mapas interactivos y colecciones de datos espaciales.

En la arquitectura que implementamos la gestión del proceso editorial descansa en OJS y la de los datos geoespaciales en Geonode, que a través de GeoServer provee interfaces OGC. De esta manera los mapas interactivos se incrustan en las galeradas de texto como objetos de OpenLayers o de Leaflet, que consumen datos utilizando las interfaces referidas.

Consideramos que el diseño e implementación propuestos ofrecen una solución innovadora a la publicación de mapas y datos geo-científicos en el contexto de las publicaciones científicas existentes (ver Mildorf et al., 2014; Brus et al., 2015; Journal of Maps, 2017). Cabe resaltar los siguientes elementos que resultan inéditos: 1) el visualizador de artículos bajo la metáfora de atlas, 2) el visualizador simultáneo de texto y mapas (en sus modalidades estática y dinámica) 3) la publicación de colecciones de datos geocientíficos, y 4) la publicación de reseñas de servicios de información geocientífica y su acceso a ellos a través de conexiones OGC.

En conjunto estos elementos coadyuvarán a valorar la importancia de los mapas como producto científico y se espera que contribuyan a fortalecer las prácticas de replicabilidad, apertura y transparencia en la comunidad geocientífica. Los componentes tecnológicos de la solución propuesta se pueden reproducir a bajo costo, ya que se basa en software libre. Sin embargo, debe considerarse que la programación de mapas interactivos demanda un trabajo 


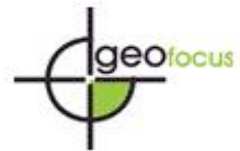

Osorno Covarrubia, J., Couturier S., López Quiroz P., Ferrari L., Martínez Zazueta, I., (2018):Terra Digitalis: diseño e implementación de una revista internacional interactiva de mapas arbitrados", GeoFocus (Artículos), $n^{\circ} 22$, p. 115-139. ISSN: 1578-5157 http://dx.doi.org/10.21138/GF.555

recurrente que es difícil automatizar, por lo que se requiere un pequeño equipo permanente para atenderla, y gestionar la revista y la IDE subyacente.

En este artículo se presentan resultados preliminares, que avanzarán durante el 2017 a la liberación de la revista. En la url http://terradigitalis.unam.mx, se puede apreciar el estado actual de la misma. En cuanto al trabajo en curso, se pretende mejorar la integración entre OJS 3 y el gestor de contenidos geoespaciales.

\section{Referencias bibliográficas}

Baranovsky, N., \& M. Zharikova (2014): “A web-oriented geo-information system application for forest fire danger prediction in typical forests of the Ukraine", en: Bandrova, T., M. Konecny y S. Zlatanova (Eds.): Thematic Cartography for the Society. Berlin, Springer International Publishing, pp. 13-22.

Brus, J., A. Vondrakova, y V. Vozenilek (2015): Modern trends in cartography: Selected papers of CARTOCON 2014. Cham, Springer International Publishing.

Caron, C., Roche, D. Goyer, y A. Jaton (2008): “GIScience journals ranking and evaluation: An international delphi study". Transactions in GIS, 12, 3, pp. 293-321.

Craglia M, de Bie K, Jackson D, Pesaresi M, Remetey-Fülöpp G, Wang C, et al. 2012 Digital Earth 2020: towards the vision for the next decade. International Journal of Digital Earth. 5(1):4-21.

Dodge, M. (2017): "Cartography in the Twentieth Century", Imago Mundi, 69, 1, pp.114-118.

Edgar, B.D., y J. Willinsky (2010): “A survey of scholarly journals using Open Journal Systems", Scholarly and Research Communication, 1, 2, pp. 1-22.

Fernández, P., J.M. Santana, S. Ortega, A. Trujillo, J.P. Suárez, J.A. Santana, A. Sánchez, y C. Domínguez (2017): "Web-based GIS through a big data open source computer architecture for real time monitoring sensors of a seaport", en: Ivan, I., Singleton, A., Horák, J., y T. Inspektor (Eds.): The rise of Big Spatial Data. Heidelberg, Springer International Publishing, pp. 41-53.

Goodchild MF, Guo H, Annoni A, Bian L, de Bie K, Campbell F, et al. 2012 Next-generation digital earth. Proceedings of the National Academy of Sciences. 109(28):11088-94.

Iosifescu-Enescu, I., M. Hugentobler, y L. Hurni (2010): "Web cartography with open standards - A solution to cartographic challenges of environmental management", Environmental Modelling \& Software, 25, 9, pp. 988-999.

Journal of Maps (2017): Journal of Maps: Aims and scope. Londres, Taylor and Francis. [Consulta: 10-01-2017]. Disponible en:

http://www.tandfonline.com/action/journalInformation?show=aimsScope\&journalCode=tjom20

Kraak, J.-M., \& A. Brown (2003): Web cartography. Nueva York, CRC Press.

Laakso, M., P. Welling, H. Bukvova, L. Nyman, B.-C. Björk, y T. Hedlund (2011): "The development of open Access journal publishing from 1993 to 2009”, PloS one, 6, 6, pp. e20961.

Mildorf, T.J. Jezek, O. Cerba, C. Malewski, S. Templer, M. Sredl, y K. Charvat (2014): "Open data platform for data integration, visualization and map design", en Bandrova, T., M. Konecny y S. Zlatanova (Eds.): Thematic Cartography for the Society. Berlin, Springer International Publishing, pp. 3-11. 
Osorno Covarrubia, J., Couturier S., López Quiroz P., Ferrari L., Martínez Zazueta, I., (2018):Terra Digitalis: diseño e implementación de una revista internacional interactiva de mapas arbitrados", GeoFocus (Artículos), $n^{\circ} 22$, p. 115-139. ISSN: 1578-5157 http://dx.doi.org/10.21138/GF.555

Muir, S.P., M. Leggott, y J. Willinsky (2005): “Open journal systems: An example of open source software for journal management and publishing", Library Hi Tech, 23, 4, pp. 504-519.

Neumann, A. (2008): "Web mapping and web cartography", en: Shekhar S. \& H. Xiong (Eds.): Encyclopedia of GIS. Nueva York, Springer, pp. 1261-1269.

Origel Gutiérrez, G., J. López Blanco, y L. Ferrari (2009): "Development and implementation of an electronic journal for publishing peer-reviewed GIS-based maps on the web", en Peterson M.P. (Ed.): International perspectives on maps and the internet, Berlin, Springer International Publishing, pp. 359-376.

Osorno-Covarrubias, J., Couturier, S., y Ricárdez M. (2015): "El rol de la Geografía y sus hibridaciones recientes frente a la crisis de sustentabilidad global", Boletín de la Asociación de Geógrafos Españoles, 69, 10, pp. 93-112.

Plewe, B. (2007): "Web cartography in the United States", Cartography and Geographic Information Science, 34, 2, pp. 133-136.

Pucher, A. (2015): "Online cartographic atlas products: learning from the past" en: Brus, J., A. Vondrakova, y V. Vozenilek (Eds.): Modern trends in cartography: Selected papers of CARTOCON 2014. Cham, Springer International Publishing. pp. 57-66.

Public Knowledge Project. Open Journal Systems Demonstration Journal (table of contents): PKP; 2018 [cited 2018 18/03/2018]. Available from: http://journals.sfu.ca/present/index.php/demojournal/index

Sluter, C.R., C.P. van Elzakker, e I. Ivánová (2016): "Requirements elicitation for geoinformation solutions", The Cartographic Journal. 53, 4, 1-14.

The White House. OMB Circular No. A-16 Revised. In: Office of Management and Budget, editor. 2002. Disponible en: https://www.whitehouse.gov/wp-content/uploads/2017/11/Circular016.pdf

Weaver, B.K. (2007): OJS in an hour: An introduction to Open Journal Systems. Vancouver, Simon Fraser University Library.

Zhou, M., R. Wang, J. Tian, N. Ye, y S. Mai (2016): “A map-based service supporting different types of geographic knowledge for the public", PloS one, 11, 4, pp. e0152881.

\footnotetext{
${ }^{1}$ Por tamaño impreso nos referimos al "tamaño de hoja" que es necesario explicitar para organizar los elementos gráficos de un documento digital -carta, doble carta, A0, A1 etc.

${ }^{2}$ El Open Geospatial Consortium (OGC) es la organización que se encarga desarrollar especificaciones abiertas de interoperabilidad para servicios de información geográfica en línea. http://opengeospatial.org

${ }^{3}$ Nos referimos al archivo de especificación del mapa; el archivo .mxd en ArcGIS o el archivo qgs de QGIS

${ }^{4}$ Las instituciones promotoras son el Centro de Geociencias, el Instituto de Geografía, el Instituto de Geología, el Instituto de Geofísica y el Centro de Investigaciones en Geografía Ambiental. Todos estos institutos forman parte de la Universidad Nacional Autónoma de México

${ }^{5}$ A petición del autor, en caso de que no disponga de los convertidores apropiados, pueden aceptarse otros formatos raster o vectoriales compatibles con GDAL ( (http://www.gdal.org/ogr_formats.html), respectivamente

${ }^{6}$ Ver Guía de Normas: Comité ISO/TC 211 Información Geográfica / Geomática. http://www.isotc211.org/Outreach/ISO TC 211 Standards Guide Spanish v2.pdf
} 